\title{
EL ROSTRO OCULTO DE LA CATEDRAL DE OAXACA
}

\author{
Manuel GonzÁlez GalváN
}

Observando con detenimiento y en varias ocasiones, la antisísmica volumetría de la catedral oaxaqueña, pudimos percibir algunos detalles estructurales en su alzado y ciertas irregularidades muy singulares en la planta, especialmente en lo que corresponde a fachada principal y primer tramo de naves, los que, a su vez, nos hicieron reflexionar acerca de un posible esclarecimiento de varias incógnitas que la construcción del monumento ha planteado y así, por medio de un análisis puramente formal de la estructura, planta y expresión plástica, deducir o llegar a una cierta respuesta objetiva de las dudas a las que no alcanzan a dar respuesta clara los documentos y la historiografía (fig. 1).

\section{El asunto historiográfico}

El problema historiográfico de la catedral que tratamos estriba en que, según algunos documentos, el edificio actual fue construido por el obispo Ångel de Maldonado entre 1702 y 1728, y así lo aceptan muchos de los historiadores, pero otros como Manuel Martínez Gracida dan fechas anteriores en casi un siglo al considerar el inicio de la obra actual en 1610, sin que falten opiniones que remontan, por lo menos parte de la estructura interior al siglo XVI, por su tipo de distribución y diseño, con lo que el lapso edilicio se amplía a tres siglos, haciendo oscura la cronología del monumento y por consiguiente su ubicación en el tiempo.

Como muestra de este vaivén en el fechamiento del templo citamos a continuación el conciso capitulillo referido a la catedral, en un también breve libro dedicado a la ciudad de Oaxaca.*

\section{Catedral}

La iglesia de San Juan de Dios sirvió como Catedral al primer obispo de Oaxaca.

* La ciudad de Oaxaca, Monografías mexicanas de arte. Texto de don Rafael Garcia Granados y del arquitecto don Luis Mac Gregor, Talleres Gráficos de la Nación, México, 1933, pp. VII y IX. 
Poco después de erigida la Diócesis, en 1535, comenzó a construirse una catedral provisional que en 1544 estaba terminada, en el mismo sitio que la existente hoy. Según el señor Martínez Gracida, el actual edificio comenzó a construirse en 1610 y se estrenó en 1730. Según don Manuel Toussaint, la actual catedral fue edificada por el Obispo Maldonado, de 1702 a 1728, y concluida por el Obispo Calderón de 1730 a 1736; este último Obispo le hizo las dos torres y la consagró en 1733. La torre del reloi fue edificada por los canónigos, durante una estancia del Arzobispo Gillow en Europa, en los últimos años del siglo pasado.

$\mathrm{La}$ apariencia exterior del templo es de gran macicez, por su escasa altura relativa y por las proporciones de sus elementos constructivos.

Las fachadas sólo se adornan con cierta riqueza en las puertas, compuestas en forma de retablos barrocos, y en las torres. La parte escultóri. ca de ellas es de mérito.

La distribución interior se hace en cinco naves, con un crucero sobre el cual hay una cúpula sin tambor, con cuatro ventanas.

Las naves están techadas con bóvedas revestidas hacia el exterior con azulejos.

Los frecuentes sismos han perjudicado notablemente esta construcción.

Por su parte don Diego Angulo Iñiguez, en su Historia del Arte Hispanoamericano, ${ }^{* *}$ refiriéndose a la catedral de Oaxaca nos dice:

su historia continúa llena de problemas capitales. El templo provisional construido a raíz de su erección en 1536 debió de ser muy pobre y estar terminado en el 1544 pero ignoramos cuándo se comenzó el definitivo; sólo sabemos que en 1550 'no estaba labrada (la catedral) o más del cuerpo solo della, e que le falta la capilla principal e torre de campanas e sacristía', y que en 1560 se continuaba trabajando en ella. Se asegura que el obispo Maldonado (1702-1728) derribó el edificio del siglo XVI e hizo labrar el actual, que terminó su sucesor levantando las dos torres. Como es difícil discernir en qué grado se imitó o se aprovechó la obra del siglo XVI, y en el interior se advierten rasgos que se refieren a esa época, describiré su organización relacionándola con la de la arquitectura de las catedrales estudiadas en este capítulo (lám. 1).

Como se puede ver, don Diego Angulo, con mucha cautela, no afirma, pero tampoco descarta la posibilidad de que el interior catedralicio provenga en parte de siglos anteriores al XVIII por ser "difícil discernir en qué grado se imitó o se aprovechó la obra del siglo XVI, y en el interior se advierten rasgos que se refieren a esa época" (fig. 2).

De igual manera, en las líneas que siguen, queremos anotar nuestras observaciones formales más como una sugerencia de etapas arqueológico-

w: Historia del Arte Hispanoamericano, Salvat Editotes, S. A Barcelona, 1955, tomo I, pp 445 y 446 
cronológicas que como una tesis documentada, pero que, en su objetividad, nos apoyan a ubicar con más clatidad temporal las distintas épocas constructivas que así dejan de ser excluyentes.

\section{Observaciones en alzado}

Lo que primero llama la atención, al exterior, es el poderoso impulso ascensional del frente tanto en la masa compacta de los cubos de torres como en la superposición de los tres cuerpos de fachada, de manera que, este subir, se hace en forma compacta y al parejo, a tal grado que las cornisas parecen los brazos extendidos horizontalmente, hombro a hombro de cada elemento, o grandes zunchos arquitectónicos para aherrojar la mole; con esto la catedral oaxaqueña compone su rostro de manera distinta al de sus hermanas virreinales en que las calles arquitectónicas y los cubos de torres se pronuncian por altibajos de más acentuado individualismo que, si bien los forman o enfilan en un frente, ponen entre ellos la barrera de los contrafuertes. Pero, en Oaxaca, el anhelo vertical se modera por temor a la amenaza sísmica y se equilibra con seguridades horizontales dando por resultado la estabilidad del cuadrado en los paramentos y el cubo en los volúmenes, lo que se hace consciente en el gran relieve Eucarístico central superior. Con estos rasgos faciales se muestra imponente y segura esta fachada capaz de proteger la más grácil danza de arcos y bóvedas de las naves, que con muy sensible altura menor, se escudan tras ella (fig. 3). Cuando se penetra al espacio interior es claramente perceptible que son dos conceptos estructurales: el de dentro, aunque sin atrevimientos de gran esbeltez, sí ofrece una relativa ligereza que lo asocia con el optimismo del siglo XVI, en tanto que el frente muestra ya la gravedad madura que, ante los sismos, sólo dan las duras experiencias, sello que especialmente se imprimió en la arquitectura regional durante el siglo XVII para finalmente alcanzar la entereza que admiramos de esta obra en el XVIII (láms. 2 y 3).

Prosiguiendo en la observación, es interesante comprobar que los cubos de torres fueron huecos conforme a lo usual y ahora se encuentran rellenados para quedar así convertidos en colosales contrafuertes angulares, lo que se corrobora al ver cómo han sido cegadas las ventanas frontales de los dos primeros cuerpos y cómo fue $\mathrm{n}_{\mathrm{i}}$, esario construir la escalera de acceso a la cubierta y campanarios a un lado de la torre norte invadiendo una de las capillas (fig. 4), y para equilibrar volúmenes y empujes se construyó, en forma simétrica, el gran contrafuerte angular 
de la torre sur, que hoy aloja el reloj, invadiendo también el interior de la capilla que corresponde simétricamente (fig. 5) (lám. 1).

Pero lo que más llama la atención, y según parece ha pasado un tanto inadvertido a críticos e historiadores, es el hecho de que el tercer cuerpo de los cubos bajo los campanarios a su vez, a la altura del tercer cuerpo de fachada y hoy también cegados fueron, sin lugar a duda, icampanarios!. Esto se comprueba y aprecia si nos fijamos en que por cada cara visible, bajo la cornisilla que corre por su parte media se perciben unos cortes verticales en los sillares de piedra a distancias regulares y que inmediatamente sobre ellos y como su continuación se notan los arranques de un arco para cara, arco al que suprimiéndose dovelas y clave por hiladas de sillares quedó muy hábilmente disimulado pero que aún así la tal cornisilla no deja de adivinarse como lo que fue, o sea, una imposta corrida, es más, también se percibe que la molduración al pie de estos cubos no es sino el desplante de las bases sobre las que se erigen los cuatro pilarones angulares que un tiempo debieron sostener los arcos abiertos y configurar el bajo y robusto cuerpo de campanas, el que en razón de su función práctica debió estar libre por sus cuatro lados. Todo esto nos lleva a suponer que el perfil del frente catedralicio fue muy distinto al actual con torres y fachada más bajas y por consecuencia proporciones de alzado más anchas que altas en relación con las actuales en mejor respuesta a las alturas de la sección transversal de las naves, posiblemente con un efecto volumétrico allanado y muy próximo al de la actual ruina de la cercana basílica de Cuilapan (fig. 6) .

Ahora bien, la siguiente lógica pregunta viene a ser, pero entonces, ¿cuándo sucedieron estos cambios y modificaciones? (lám. 4).

Creemos correcto suponer que en el primer tercio del siglo XVIII, después del terremoto sufrido por la ciudad en 1702 y justamente durante el episcopado de don Ángel Maldonado, entre 1702 y 1728, lo que aclara y deslinda su intervención en el monumento que es de suponerse concentrada en el cuerpo frontal lo que al realizarse de manera tan espectacular, transformando los viejos campanarios al grado de casi hacer olvidar por completo su perfil original y al elevar en su totalidad la gran nueva fachada que rebasa, y con mucho, a la que antes pudo haber existido, dio la impresión, y así ha quedado consignado, de que rehizo todo el templo y más cuando al parecer hubo una obra de reforzamiento en muros y contrafuertes pues se perciben algunos arcos botareles también rellenados y hasta renovados (fig. 7 ), pero es difícil de creerse que con los medios que por entonces se contaba se haya podido realizar tan basta obra en escasos veintiséis años y más aún cuando el concepto espacial del in- 
terior, con peraltada nave central y crucero, acerca más la solución arquitectónica de esta catedral a los esfuerzos que sus hermanas de México, Puebla y Morelia realizan durante el siglo XVII, lo mismo que las portadas del crucero cuya expresión estilística, de sobrio y fino acabado, delatan la misma centuria decimoséptima en que nuestro barrroco aún voltea el rostro hacia resabios manieristas $\mathrm{y}$, en este particular caso oaxaqueño, a los aún más lejanos del plateresco como sucede en las columnas del tercer cuerpo (fig. 8), estilística muy distinta a la eclosión barroca dieciochesca de la fachada principal, en la que más adelante nos volveremos a detener para analizar esta faceta.

Ahora bien, si continuamos observando la fachada catedralicia, tanto en su parte frontal exterior como por el interior de las naves laterales y sobre las bóvedas el reverso del imafronte, podemos anotar algunos detalles que confirman lo dicho en líneas anteriores, es más, dos o tres elementos hacen indudable que hubo severos cambios y mayor elevación de la fachada actual (fig. 7). En el cubo de la torre sur y en su cara que ve a la plaza, tercera sección, aún puede percibirse, sobre todo con el sol rasante del medio día, el círculo de la rasurada carátula del primitivo reloj, un cuerpo más abajo que el actual, correspondiente justamente bajo lo que debió ser cuerpo de campanas (fig. 5). En este campanario cegado, es además claramente perceptible la continuidad circunvalante que tuvo su molduración por sobre el extradós de las bóvedas de naves laterales, lo que obviamente testifica que este cuerpo fue exento y no adosado a la fachada como ahora se muestra y de igual manera se revela en la torre norte (fig. 9).

Es más, quizá la mejor prueba de los cambios de altura y adaptación de la actual fachada a la estructura preexistente de las naves, se muestra elocuente en las dos ventanas elípticas que se abren sobre las puertas de acceso a las naves laterales. Estas ventanas parecen interrumpir bruscamente, y exactamente en su altura correspondiente, la cornisa del primer cuerpo que se ve obligada a colgarse y quebrarse poligonalmente de manera poco lógica y usual puesto que queda directamente sobre las claves de los arcos de ingreso, al igual que pasa con el tramo central de toda la fachada, donde aprovechándose la mayor altura del arco mayor, la cornisa corre recta pero directamente también sobre la clave, omitiéndose el arquitrabe y friso (lám. 3).

La explicación a esta aparente anomalía se encuentra de inmediato al penetrar en el templo y apreciar el gran derrame interno que delata el espeso grosor del muro y cómo las ventanas elípticas no pueden estar ni más arriba ni más abajo, pues más arriba rebasarían la altura de las bóvedas 
y más abajo chocarían con los arcos de entrada, todas estas circunstancias son sintomáticas de la mayor antiguiedad interior del monumento que ya no podía ser modificado (fig. 10). Además, el gusto por el trazo elíptico se asocia más con el siglo XVII que con el XVIII, un ejemplo de ello son las ventanas elípticas de la nave mayor de la catedral de Morelia que datan de esa centuria.

Un detalle más, en abono a lo considerado, es que entre los cubos de torre actuales y el despliegue de la gran fachada, o sea en la ascendente línea y punto de contacto entre la parte ornamentada y la lisa no se ob. servan coincidencias de resaltes o molduración, ni amarres o contrapeo de los sillares de piedra y tan sólo la cornisa del extremo superior pugna y pretende subrayar en lo alto la unidad del conjunto (fig. 11).

Por estar tratándose aquí de meticulosidades, cabe recordar ojos tan avizores, como los de José María Velazco que en observación plástica se nos adelantan, así acontece en su conocido cuadro de La Catedral de Oaxaca (1887), donde como genial pintor que fue, observa hasta el último contraste de tonos cromáticos y registra en las juntas de la piedra verde oaxaqueña los hilos más blanquecinos de la mezcla con lo que queriendo, o sin querer, tan sólo por agudeza visual registra algunos de los cambios que la fachada catedralicia ha sufrido y que aquí, con mayor detenimiento, tratamos de analizar.

\section{Experiencia sísmica en Oaxaca}

En su ya secular existencia, es sin duda Oaxaca, entre nuestras ciudades antiguas, la que mejor representa con sus monumentos una arquitectura que conjuga la búsqueda de la belleza con el ingenio belicoso por conservarla contra el reto imprevisto de los temblores. Así, y hablando de fachadas, se encuentra que en tan sólo el área urbana de la ciudad se han buscado, y encontrado, diversas soluciones que permiten la sobrevivencia de los rostros arquitectónicos, especialmente de los templos.

Desde luego que la arquitectura civil no ha permanecido ajena a sobresaltos y preocupaciones de índole sísmica, pero con economía de medios y desglose de experiencias ha llegado a la seguridad que proporciona la parquedad de escasas fórmulas acordes con las técnicas ancestrales de piedra sobre piedra y cementante adherente; escasa altura, gruesos muros y contrafuertes, espacios cúbicos o esféricos, vanos de tendencia cuadrada con robustas jambas y dinteles que llegan a tener de un medio a un tercio de la dimensión del hueco para así asegurar física y sicológicamente la 
seguridad de permanecer inhiestos aún en las peores sacudidas. Mas, con la arquitectura religiosa no sucede lo mismo, por comunitaria y necesariamente de espacios más generosos y convincentes de grandiosidad espiritual, se tiene que intentar una mayor variedad de recursos de permanencia expresiva y estructural.

De esta manera la ciudad de Oaxaca, tan sólo en las fachadas de sus iglesias, es un muestrario de sugestiva dialéctica constructiva al grado de hacernos asociar, por una cierta concordancia esquemática, algunas letras mayúsculas del abecedario con la proyección volumétrica, especialmente en planta, de algunas de estas iglesias, así se podrían considerar unas relaciones regidas por libertad imaginativa a saber:

La Soledad con la letra C, por su fachada biombo que recibe al visitante con una concavidad de ábside abierto y sacralizante del espacio exterior, o como retablo que al aire libre se acuna con el arrullo y empuje de los contrafuertes extremos que le dan refugio y seguridad (fig. 12) (lám. 5).

La Compañía se expande, tanto en la fachada mayor como en la portada lateral a la manera de una $\mathrm{D}$, hinchando su pecho en el que se acorazan las singulares y anacrónicas columnas oaxaqueñas candelabro del plateresco en la parte baja, sin negarse a portar sobre ellas pilastras estípites de gentilicio barroco, los que a su vez, sin desdoro, hacen de canéforas a un entablamento y frontón neoclásico; raro pero armónico eclecticismo obligado a hermandad por el susto y común enemistad de los temblores (figs. 13 y 14) (lám. 5).

La Catedral, con sus vaivenes reconstructivos, con su reforzamiento y avance volumétrico de las tres calles de la parte central de su pujante fachada, nos remite a una especie de letra E, de muy grueso trazo, donde las barras extremas son las torres y la central la portada mayor. $O$, también, tridente despuntado aunque diseñado para trillar almas (fig . 3) (lám. 5).

Los Principes, exagerando las referencias al abecedario podría decirse que esta fachada es una letra $\mathrm{K}$, pues a la sencilla portada que originalmente tuvo, con breve atrio al frente, éste se le suprimió creando un vestíbulo y pórtico artificial en planta baja y ampliando el coro en lo alto, así los dos pilarones del actual pórtico serían los extremos de la letra $\mathrm{K}$, en tanto que sus brazos los arcos que a modo de botareles recargan perpendiculares sobre la fachada preveen, en su aparente indolencia, los posibles sismos (lám. 5).

El Carmen Alto, por razón de reglas usuales de la Orden Carmelitana, desde su inicial construcción cuenta con un nartex con frente de tres ar- 
cos y dos laterales que en mucho le ayudan a ser supérstite de temblores; el relieve de la protección de la Virgen del Carmen, en un enmarcamiento de fórmula cuadrada, reitera todo lo antedicho.

San Francisco, en su estilística de barroco estípite, más a la manera del centro del país, sin embargo, resiente el subsuelo oaxaqueño y para su mayor tranquilidad cubre su fachada con una combinación de ArcoSolio, con ligero biombo bajo él, o forma de retablo absidal cóncavo que le da mayores garantías de supervivencia (lám. 5).

La mayoría de las otras iglesias citadinas sí se sujetan a las comunes soluciones de planimetría del resto del país donde los sismos no son tan angustiantes, no obstante, en Oaxaca, subsiste una constante de robustez y preocupación "por lo que pueda suceder".

\section{Del estilo}

Es inobjetable que el estilo de la catedral oaxaqueña es barroco, pero. . . del barroco tan variado, ¿a cuál modalidad pertenece?; pues, sin duda, a la que sugiere mayor resistencia y, en esto, se remite al más lejano clasicismo en que el fuste de las columnas se estructura por tercios que van decrecientes como fórmula de mayor resistencia a la carga vertical y aún al posible esfuerzo o sacudimiento horizontal, de aquí el acierto de emplear en Oaxaca la modalidad barroca de la columna tritóstila que marca tercios de su fuste con racional y milenaria tradición clasicista (fig. 11).

En su atrevido y original avance tanto hacia el frente como a lo alto, la fachada catedralicia oaxaqueña resulta ser una marcha contra los sismos, con sus treinta medias muestras de columnas perfectamente disciplinadas y fundidas, como una sola, diríase en términos castrenses, para resistir al enemigo y, ihay que ver cómo la columna tritóstila precisamente eso representa y le dio origen con su clásico vigor inferior y aligeramiento con acción más libre en la parte superior hasta llegar al capitel!

¡No en vano el barroco oaxaqueño está impregnado de tal sentido de lógica, tradición y estética que dentro de la modalidad del barroco tritóstilo, tiene en la catedral su culminación!

\section{Apunte iconográfico}

En esta anotación comenzamos por considerar que la gran fachada mayor es autónoma en su expresión iconográfica, como la hemos considera- 
do en lo constructivo, por tanto las únicas dos esculturas que aparecen en las portadas de los cruceros no parecen tener relación iconológica con ella, siendo, además, cronológicamente anteriores, no obstante conviene consignarlas a saber:

El único nicho de la portada del crucero norte contiene una escultura exenta que al parecer representa a San Pablo pues tiene sus rasgos iconográficos, con luenga barba, atavios o ropaje de apóstol, libro en su mano izquierda y levanta el brazo derecho con su mano que, aunque rota, muestra una espiga para puño que debió sostener la metálica espada (fig. 15).

Por su parte la portada de igual diseño correspondiente al crucero sur, aloja en su nicho una indudable y bella imagen de Santa Rosa de Lima, con su ancla portuaria en mano izquierda y, en la derecha, el Niño posado entre el ramillete de rosas (fig. 8). Como simple nota de singular presencia, están los dos escudos de España, con todo y sus columnas de Hércules o del Non Plus Ultra, que rematan ambas portadas y que, icómo escaparon a la torpe ley de 1823 que ordenaba su desaparición!, o, ¿es que son una reposición?

Pero, como lo que centra nuestra atención es la fachada mayor, pasemos a intentar consignarla, primero, tan sólo en su carácter iconográfico apuntando su imaginería (fig, 16).

1. Gran relieve central de la fachada que muestra el Patrocinio de la catedral que es, La Asunción de la Virgen. En este caso, como en muchos otros de la iconografía del arte colonial, se funde La Asunción con la Coronación en los cielos efectuada por la propia Santísima Trinidad; exaltación mariana dilecta al mundo hispánico. Todo sucediendo ante la extasiada contemplación de los apóstoles que, por ser ellos a su vez representación de la Iglesia, justifican el culto mariano.

2. San Pedro, fácil de identificar por sus conocidos atributos, aunque sus llaves han desaparecido de su rota mano derecha. Su colocación al costado derecho de la puerta principal, le corresponde como lugar de honor.

3. San Pablo, aunque con mutilaciones en la escultura, con brazo derecho roto desde el codo, con la izquierda sostiene la espada que se apoya en el piso y lleva venera pequeña bajo el puño. Es obvia su representación iconográfica.

4. San José, con el Niño en brazos, en coloquial y tierna representación.

5. Santiago el mayor, con dos veneras o conchas en su esclavina, en la mano izquierda tiene un libro que entreabre con un dedo y en la de- 
recha sostiene delgado báculo de hierro, de éste ha desaparecido el guaje de peregrino.

6. Santo obispo por llevar mitra. Con la mano izquierda sostiene un libro cerrado con el que a la vez se recoge la capa pluvial. Levanta su brazo derecho con mano enguantada. Está en actitud de prédica o bendición aunque también parece lleva un objeto esférico. ¿Es San Agustín con su corazón flechado en alto?

7. Santo portando en la mano izquierda un libro. La derecha levantada en señal de prédica o bendición, pero está rota. Sobre el libro se perciben dos bolitas, ¿o piedras?, parece faltar una más. Luce capa pluvial y una especie de solideo. ¿Es San Jerónimo con sus ropajes cardenalicios, pero con las piedras que se daba golpes de pecho, según su iconografía?

8. Clérigo con birrete y palma de martirio sostenida con las dos manos. Muestra dos largas estolas como de lino planchado en zigzag. Sobrepelliz ligera, barba y bigote. Lo enaltece un cortinaje. Por su difícil identificación, ¿constituye tan sólo la arquetípica representación de cómo el sacerdocio debe abrazar su ministerio hasta el grado del martirio?

9. Clérigo con birrete, mangas largas y estola como de lino planchado en rugoso. Sobrepelliz ligera, barba y bigote. En la mano derecha palma de martirio y en la izquierda Crucifijo que contempla. Esta fórmula iconográfica no hace dudar que es la representación de San Juan Nepomuceno. Como su compañero en simetría, lo enmarcan cortinajes de rígidos pliegues.

10. Arcángel con casco emplumado, peto a pechera más con aspecto como de cuero, por lo untuoso, que de metal. Con la mano derecha sostiene bastón de mando o espada metálica. Varias mutilaciones dificultan su identidad, especialmente la ausencia de su rostro, sin embargo debe ser San Miguel.

11. Arcángel con un sombrero tipo solideo, aunque emplumado. En la mano derecha porta una rama de azucena y rosas, en tanto que con la izquierda sostiene un espejo ovalado. Debe ser San Gabriel.

12. Relieve que culmina el eje central de la fachada, en él, bajo cortinaje o dosel que extienden dos angelillos niños, irradia la Eucarística Custodia, sobre trono o manifestador barroco en el que el frontal, sobre bordado lienzo o metálico y repujado ajuar litúrgico, muestra en relieve un corazón alado con las siglas, IHS en su centro, por lo que en mucho recuerda por esto, los que penden y laten en las cruces de Yalalag. 
Dos clérigos que han perdido literalmente la cabeza, incensan el culminante Misterio Eucarístico.

\section{Factura artística}

En el gran despliegue de relieves y esculturas exentas que ofrece la noble fachada oaxaqueña, desde el punto de vista de factura u oficio artístico se perciben, por lo menos, tres manos de escultor. Uno primero sería el que realiza los relieves de los dos santos clérigos sobre los óculos elípticos de las puertas extremas, con un cierto acartonamiento y rigidez en los paños. Otro sería el del relieve del Patrocinio con la Asunción-Coronación de la Virgen y de la Adoración del Sacramento en lo alto del eje central, ambos relieves de rica y vibrante textura barroca. Quizá también a este cincel se deban los dos arcángeles que culminan las calles arquitectónicas laterales, con tan atrevido y vigoroso altorrelieve que sus alas parecen estar a punto de abandonar el muro tras ellas y desprenderse para emprender el vuelo. Una tercera sensibilidad, de gusto más compacto y reposado, aunque sin rigideces, parece informar las esculturas exentas de los seis nichos a los lados de la calle central (fig. 16).

Sin embargo, y como es lo usual en este tipo de obras religiosas, el mensaje didáctico o iconológico, funde en unidad las posibles o aparentes diferencias de calidad plástica.

Un curioso detalle de toda esta imaginería la constituye el que, con excepción de la Virgen en su relieve y la Custodia Eucarística, ininguna de las imágenes tiene aureola de santidad!

\section{Sugerencia iconológica}

Por último diremos que, sin pretender hacer un examen completo o exhaustivo del mensaje iconológico que debe guardar la gran fachada catedralicia, no podemos dejar de preguntarnos o sugerirnos: ¿Qué nos quiere decir el bello rostro del Templo? Y la respuesta es quizá más sencilla, y menos elaborada de lo que podría pensarse.

Veamos: en torno al Patrocinio del Templo; La Asunción de María, la Iglesia la exalta, venera y hace una exégesis de su propia organización y autoridad como corresponde a un monumento erigido por el clero secular. Así, en el cuerpo bajo o inferior, que sirve de base, las tres claves de los tres arcos de acceso a las naves muestran la Tiara pontificia sobre 
el libro de la base doctrinal y la autoridad de las llaves del Reino junto a ello. Pedro y Pablo ( 2 y 3 ) son: Pedro la autoridad depositada en Él por el propio Cristo y Pablo el gran converso que de persecusor se convierte en difusor. Sobre ellos (4 y 5), San José, protector de Cristo y de la Iglesia, como patrono universal que lo es de Ella y Santiago Apóstol, gran difusor del Cristianismo hasta el "finisterre", patrono de España y por tanto de su obra evangelizadora. ¿San Agustín y San Jerónimo? (6 y 7), santos doctores de la Iglesia y sabios intérpretes de la verdad doctrinal. Agustín abandona la falsedad religiosa del pensamiento antiguo. Jerónimo medita, traduce, sufre y se arrepiente consolidando así con vida, ejemplo y pensamiento la verdad cristiana.

Los dos clérigos ( 8 y 9 ), con sus palmas del martiro, su sencillez y su falta de espectacularidad, son buen ejemplo de cómo el cumplimiento del deber sacerdotal debe ser tan importante como discreto y casi anónimo. Y... los dos vigorosos arcángeles: ¿Miguel y Gabriel? (10 y 11), en lo alto adoran al Señor, pero también asisten a la Iglesia; Miguel como príncipe de las huestes celestiales y representante de la Justicia Divina; Gabriel, el Nuncio de la Redención y la Misericordia Divinas por anunciar al Redentor.

Por último, al centro, en lo alto, preside al tiempo y al espacio, el Misterio Eucarístico de la custodia con la Hostia. Cristo, Dios hecho hombre redime al género humano y en medio de él, con él se queda en este católico misterio llamado "del amor". 
DOI: http://dx.doi.org/10.22201/iie.18703062e.1987.58.1370

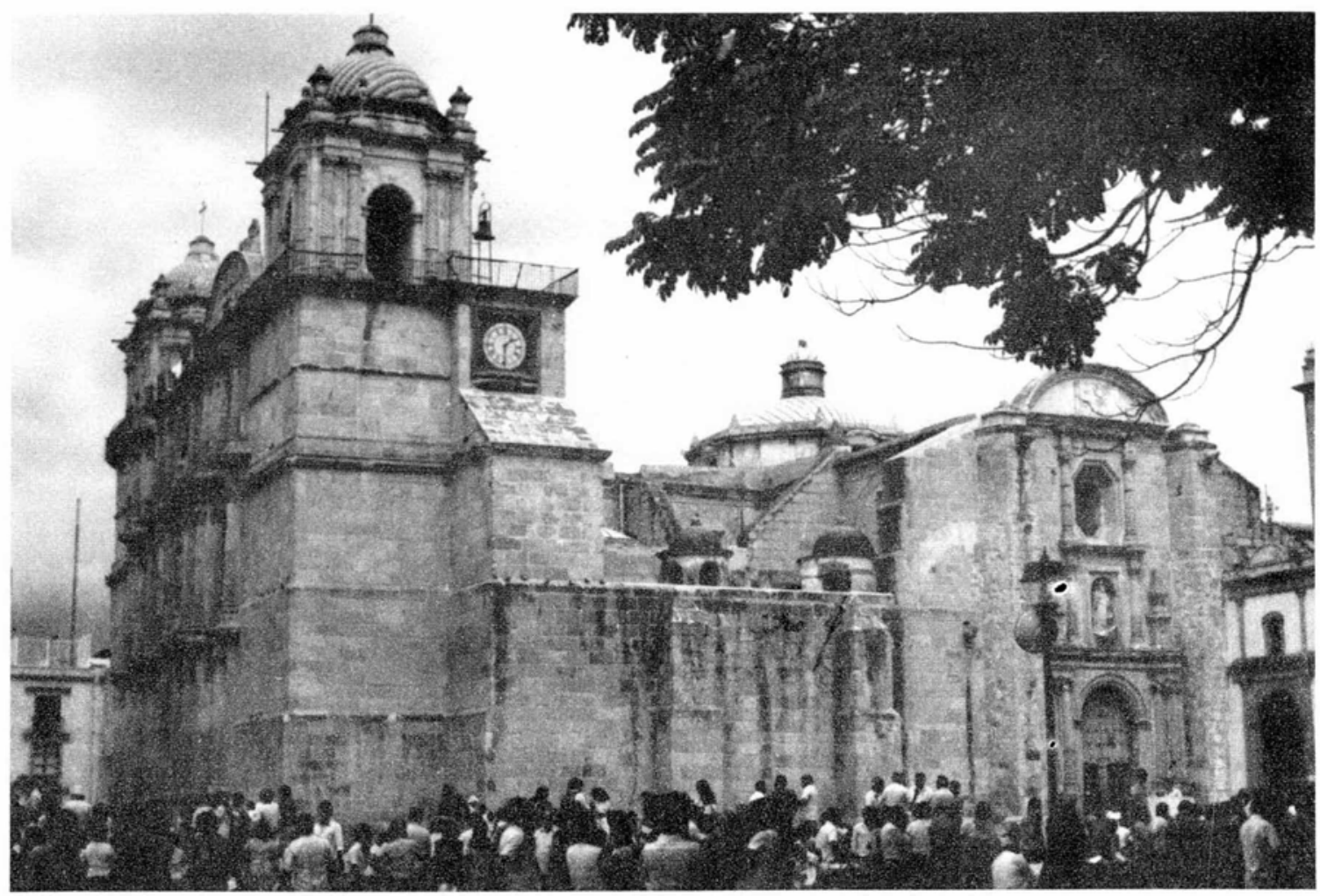

Figura 1. Catedral de Oaxaca vista en su costado sur. 


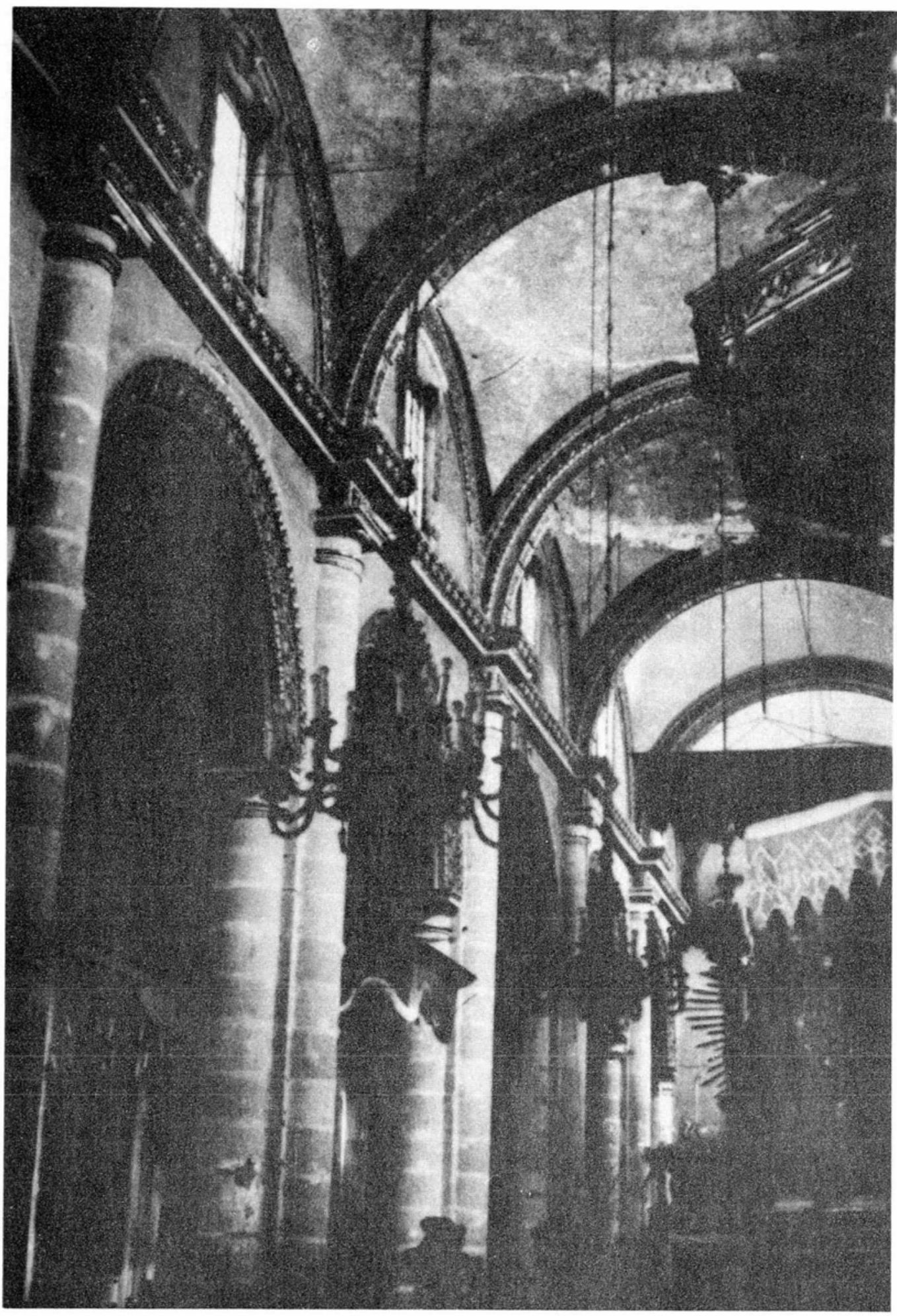

Figura 2. Interior de la catedral. Nave central. 


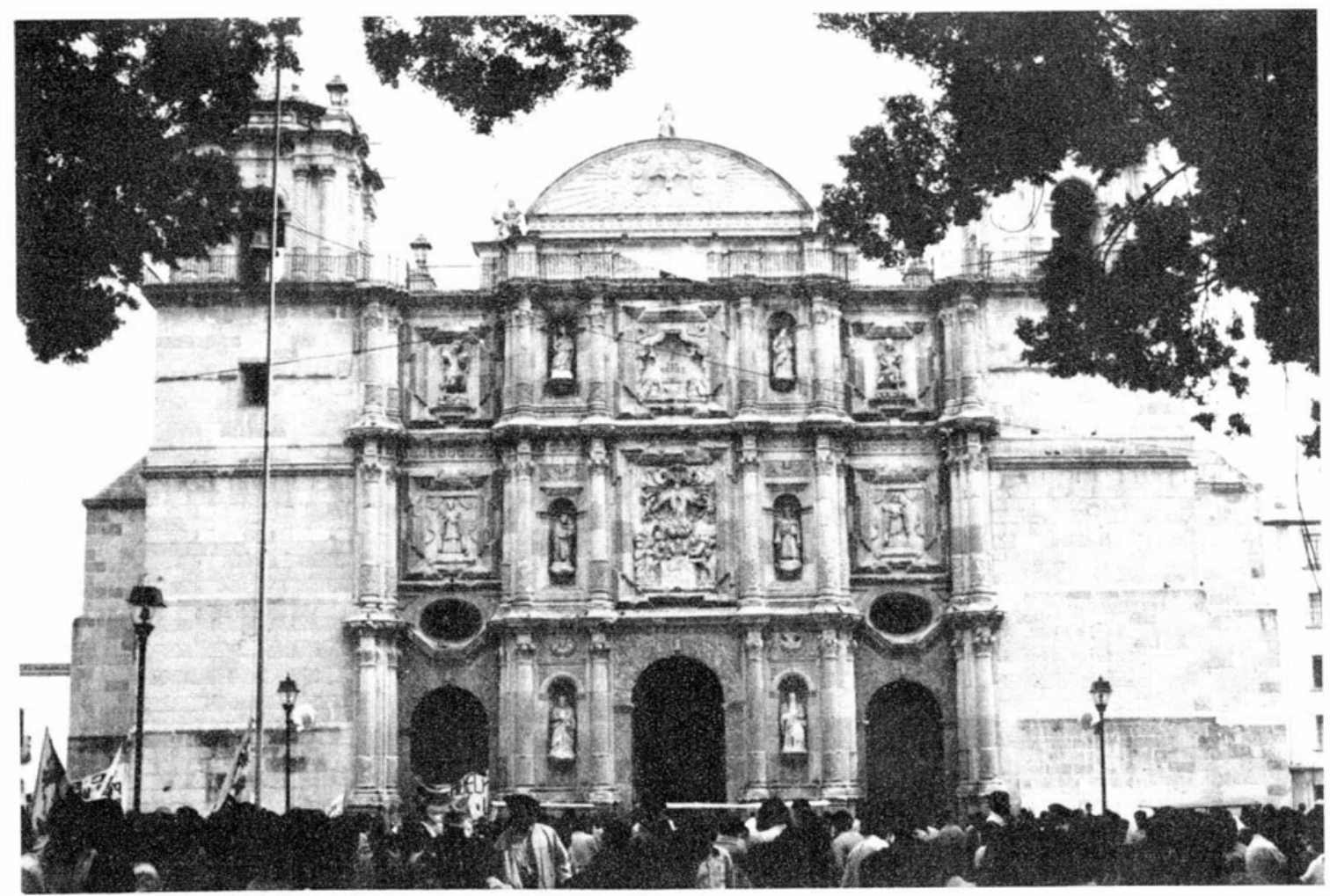

Figura 3. Fachada mayor de la catedral. 


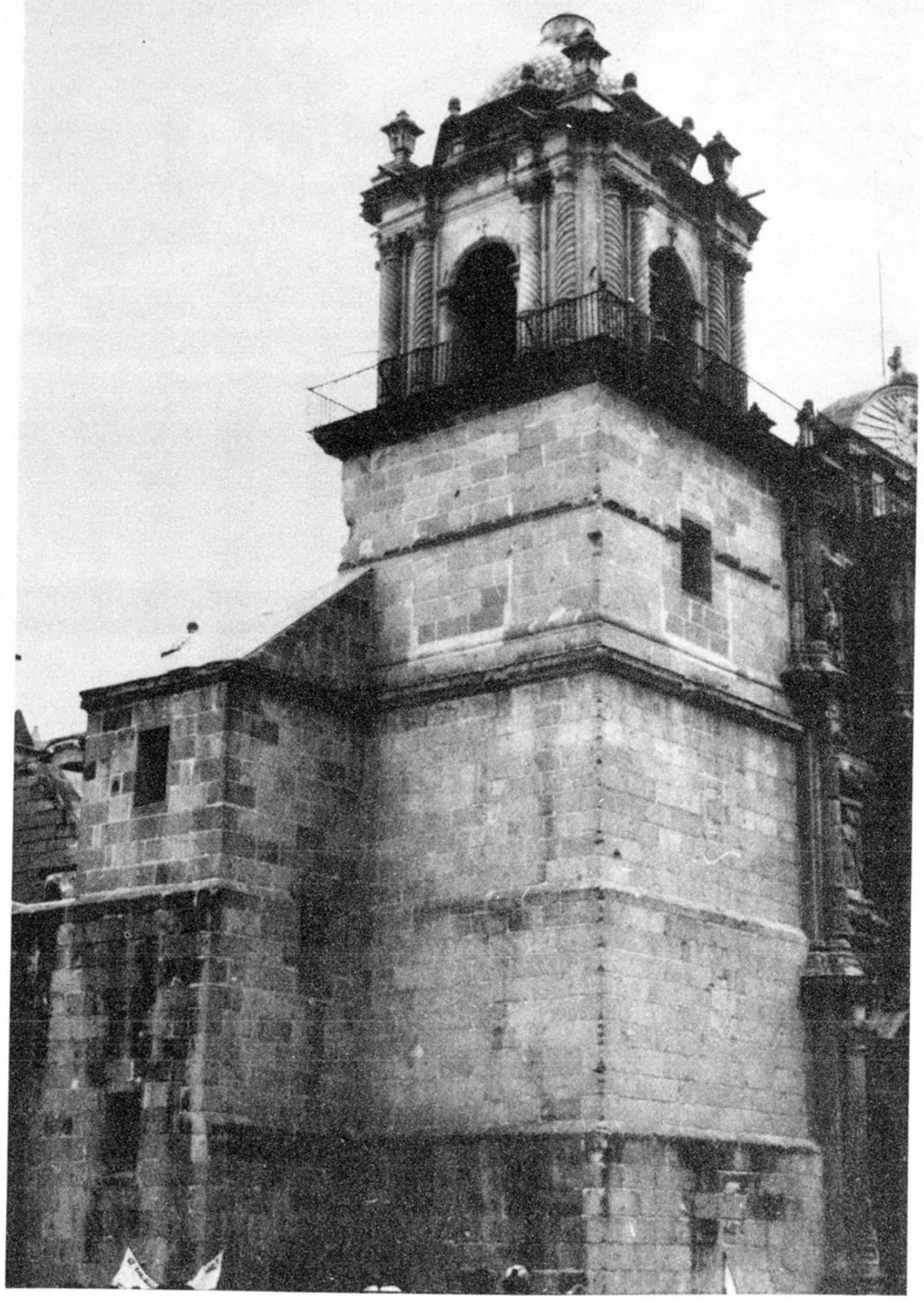

Figura 4. Torre del lado norte con acceso a las bóvedas y campanarios. 


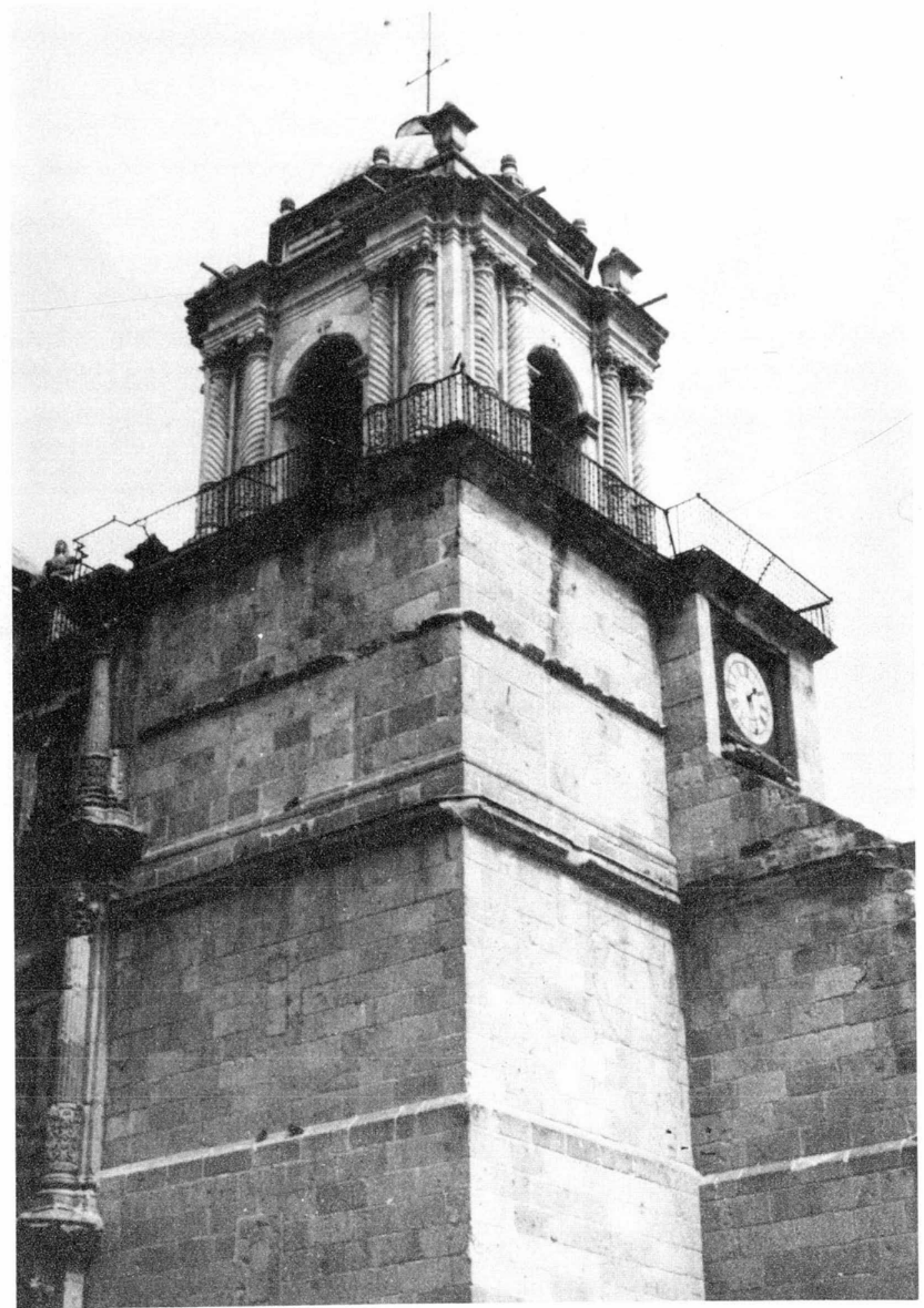

Figura 5. Torre del lado sur, con la huella de la carátula del primitivo reloj en su parte media y la presencia en lo alto del nuevo. 


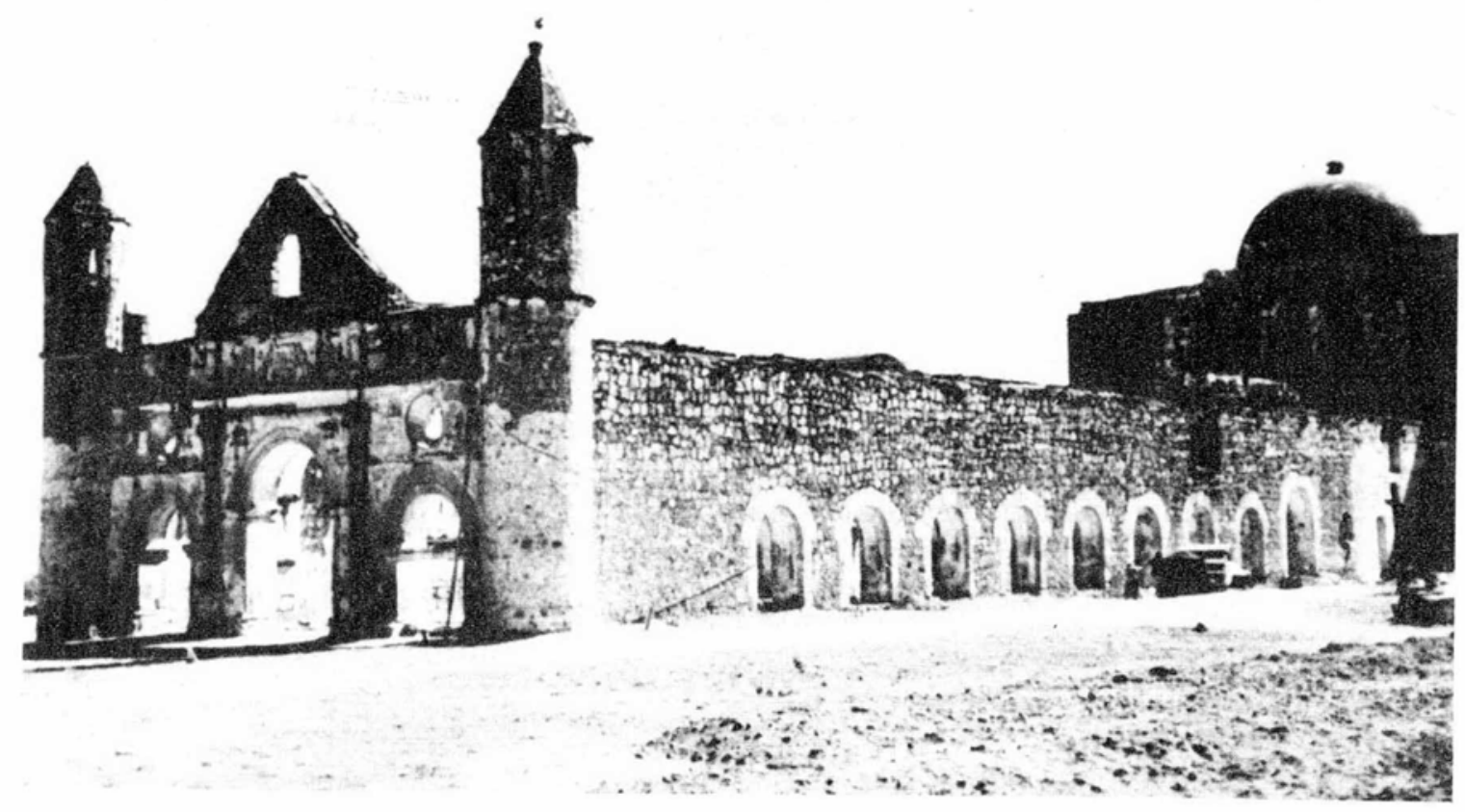

Figura 6. Ruinas del templo basilical de Cuilapan, Oax. 
DOI: http://dx.doi.org/10.22201/iie.18703062e.1987.58.1370

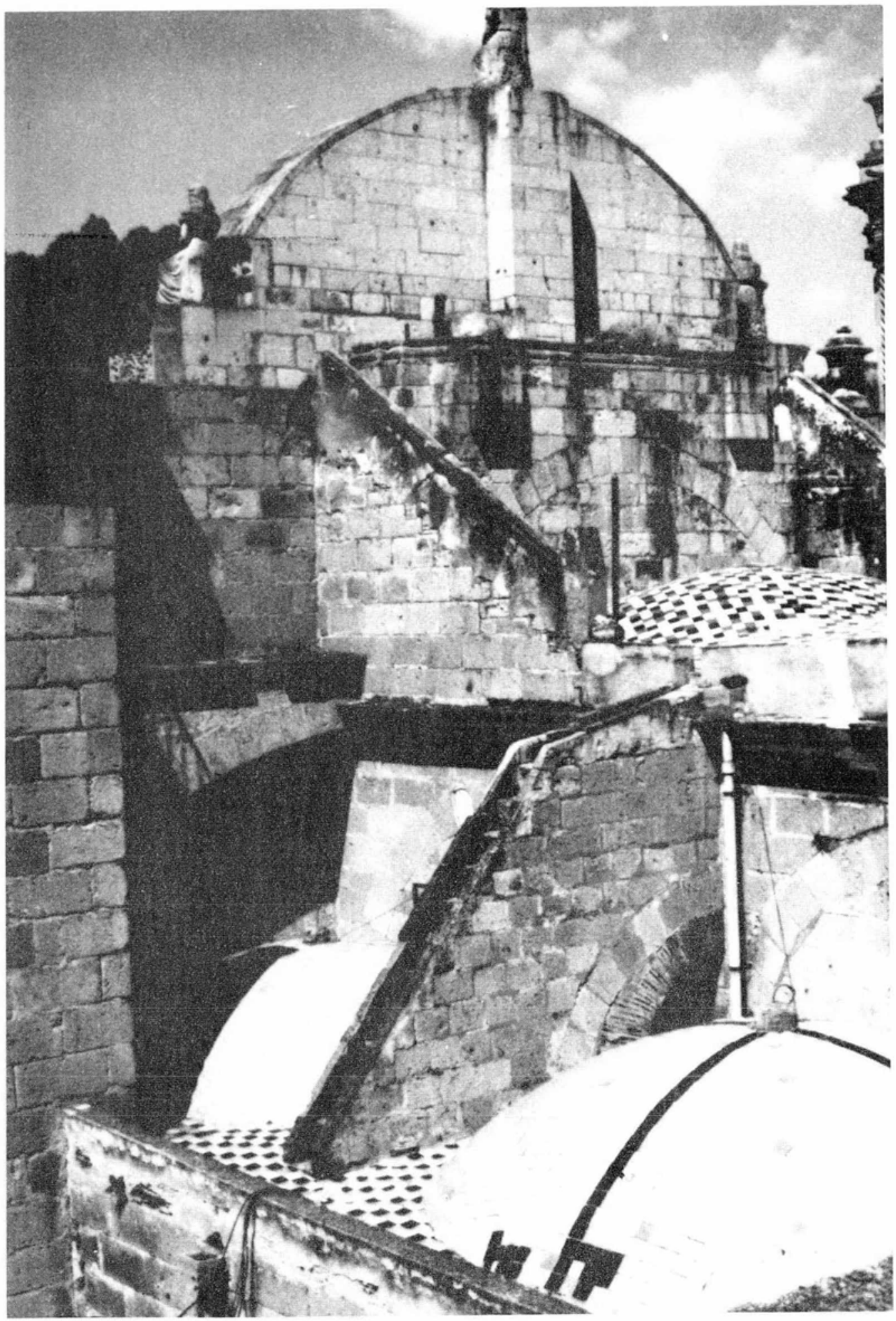

Figura 7. Reverso de la fachada mayor e imafronte de la catedral. 


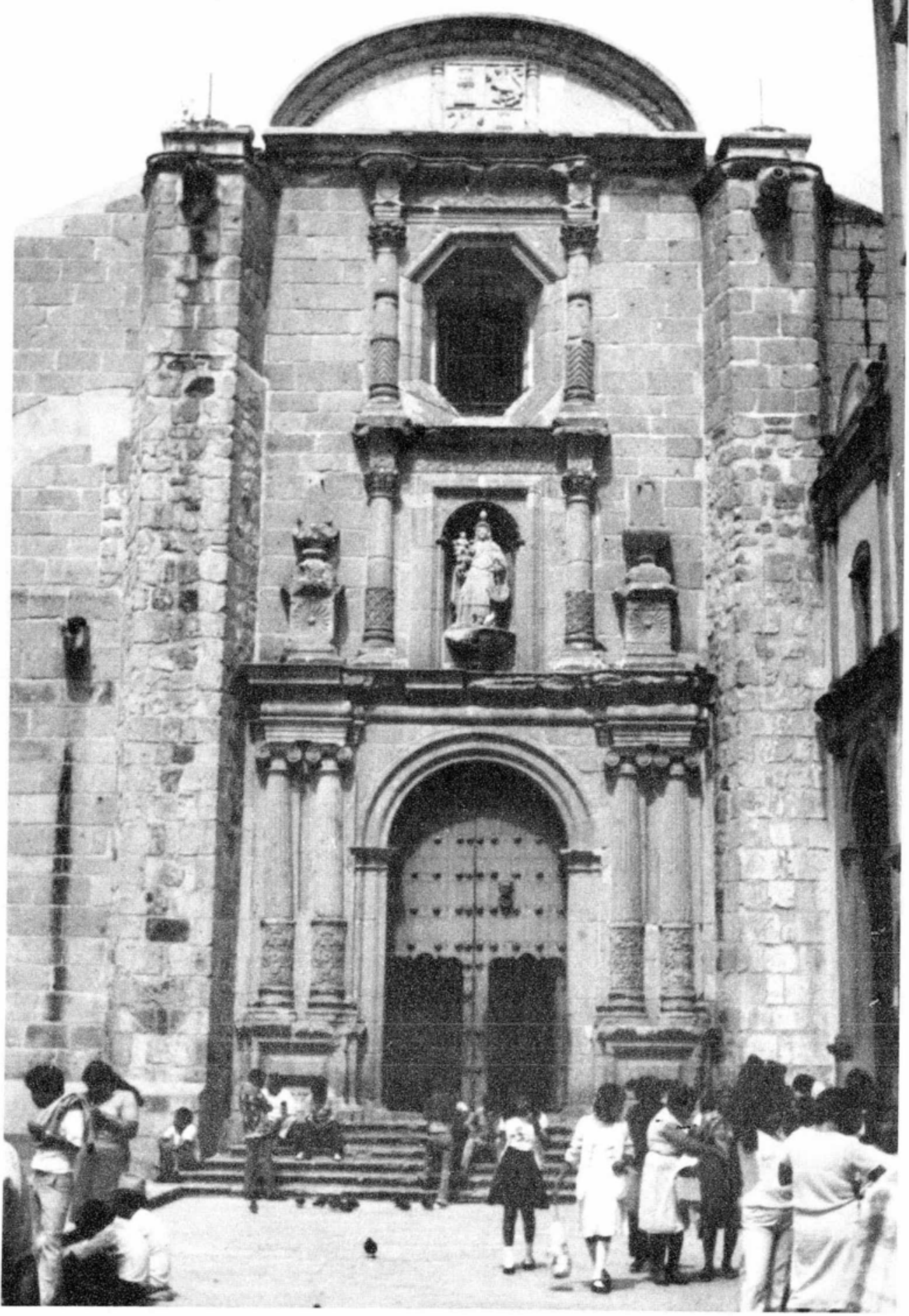

Figura 8. Portada del crucero sur de la catedral. 


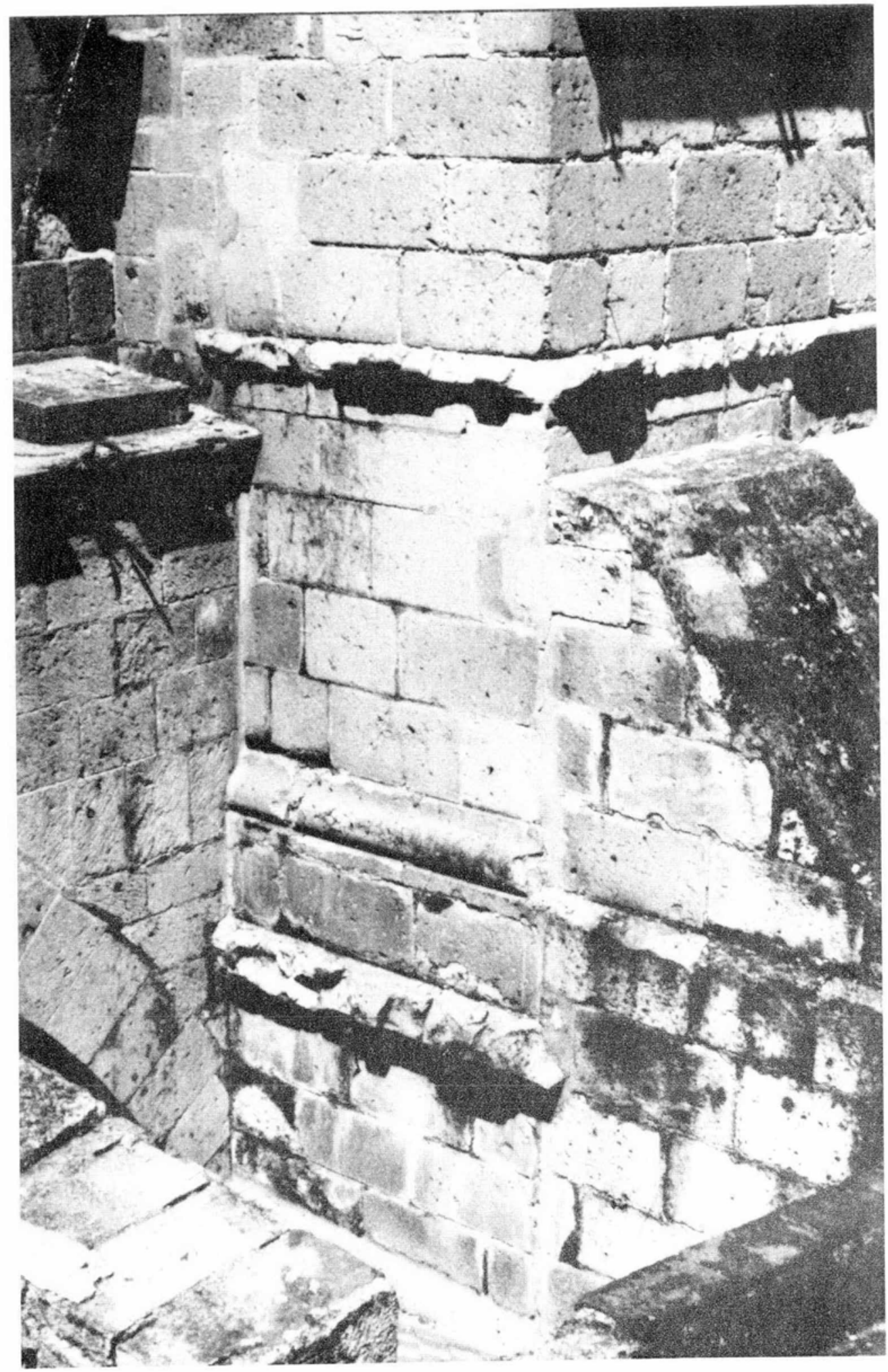

Figura 9. Ángulo sur-oriente, sobre las bóvedas en la torre norte. 


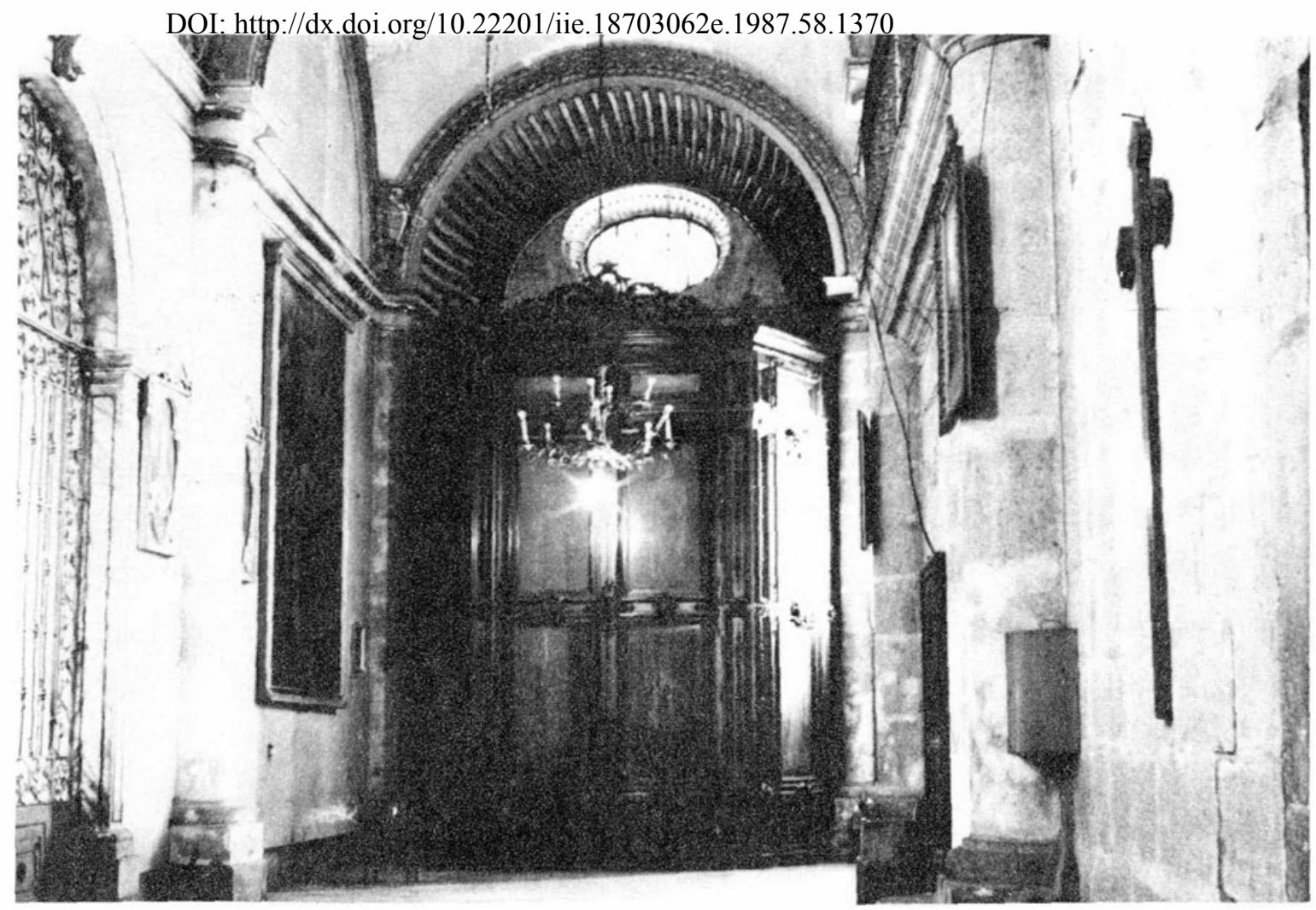

Figura 10. Nave lateral sur de la catedral, vista interior hacia la puera de entrada. 


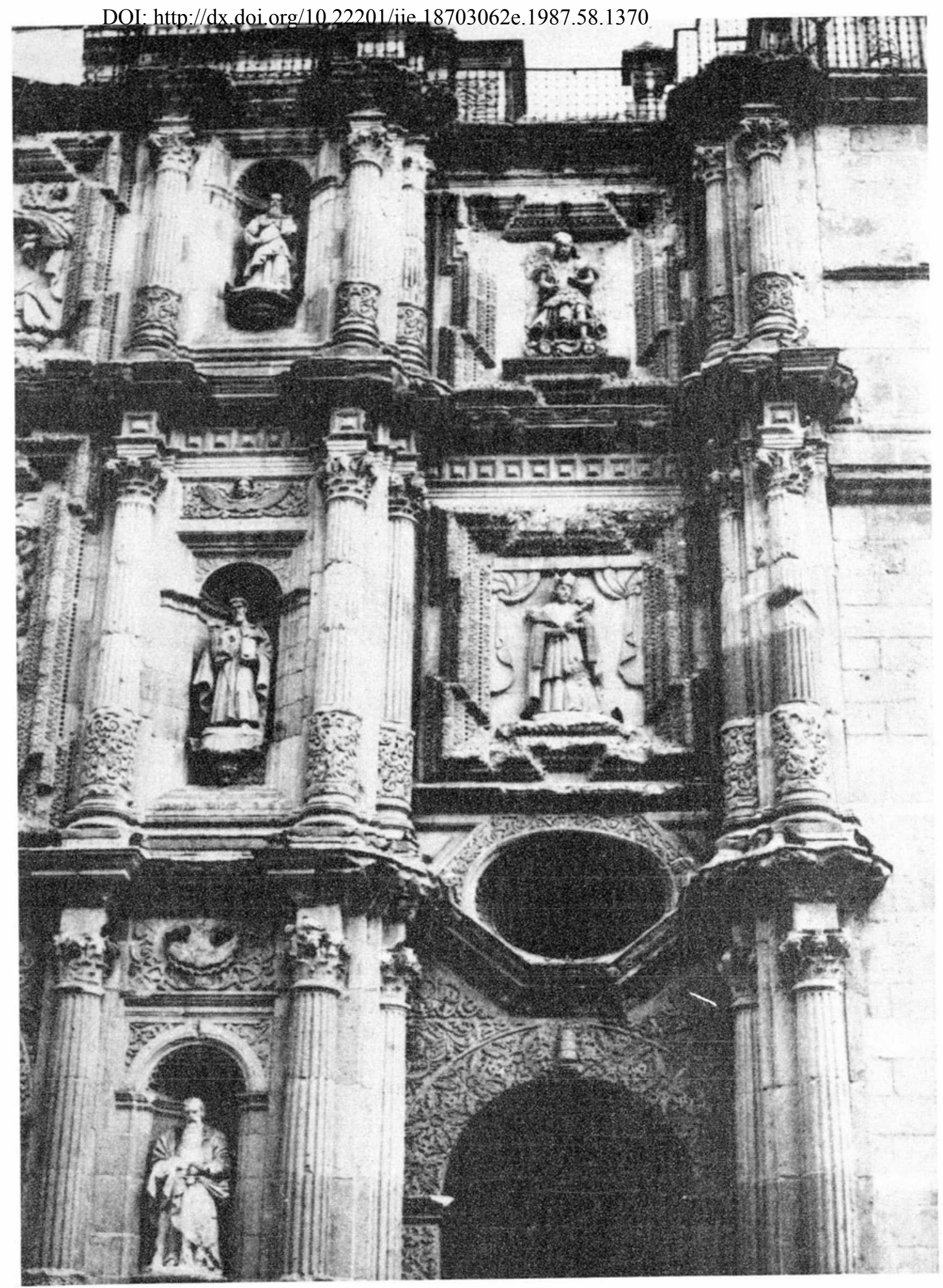

Figura 11. Extremo sur de la fachada mayor. Se percibe la falta de amarres o trabazón de los sillares entre los paramentos lisos de la torre y las partes ornamentales. 
DOI: http://dx.doi.org/10.22201/iie.18703062e.1987.58.1370

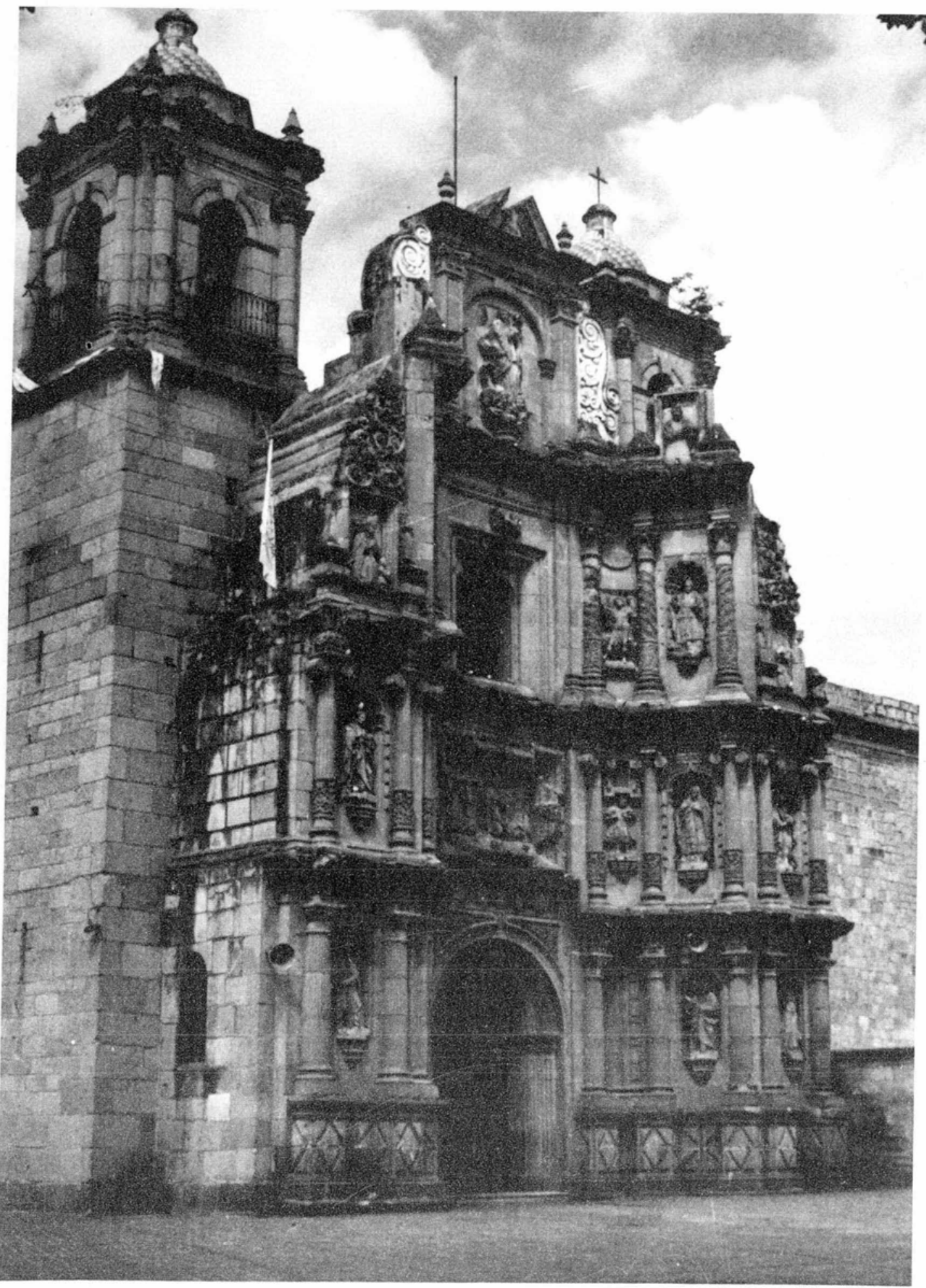

Figura 12. La iglesia de La Soledad, con su eficaz y antisísmica fachada biombo. 


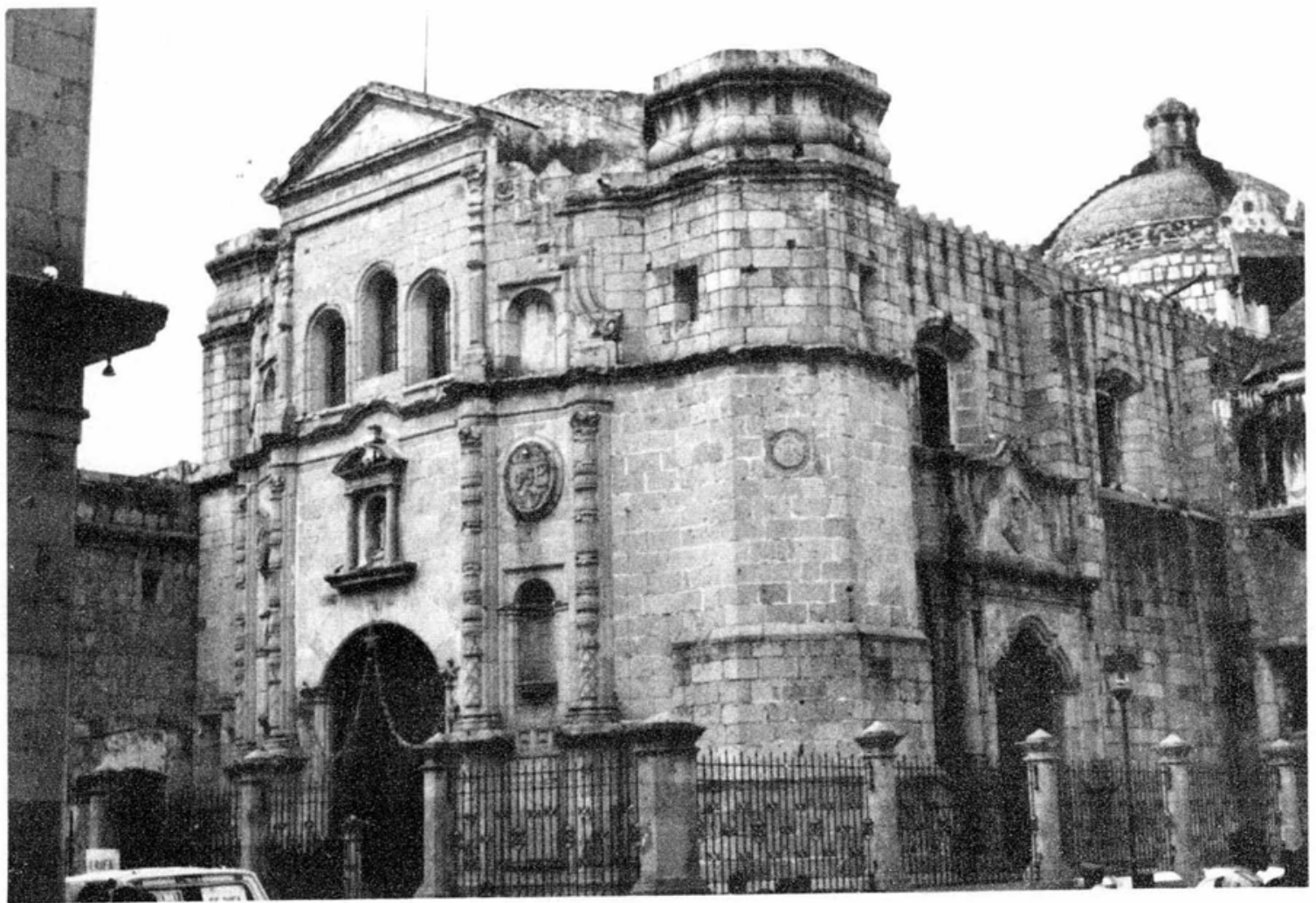

Figura 13. La iglesia de La Compañía, con el avance volumétrico convexo de su fachada principal y portada lateral. 
DOI: http://dx.doi.org/10.22201/iie.18703062e.1987.58.1370

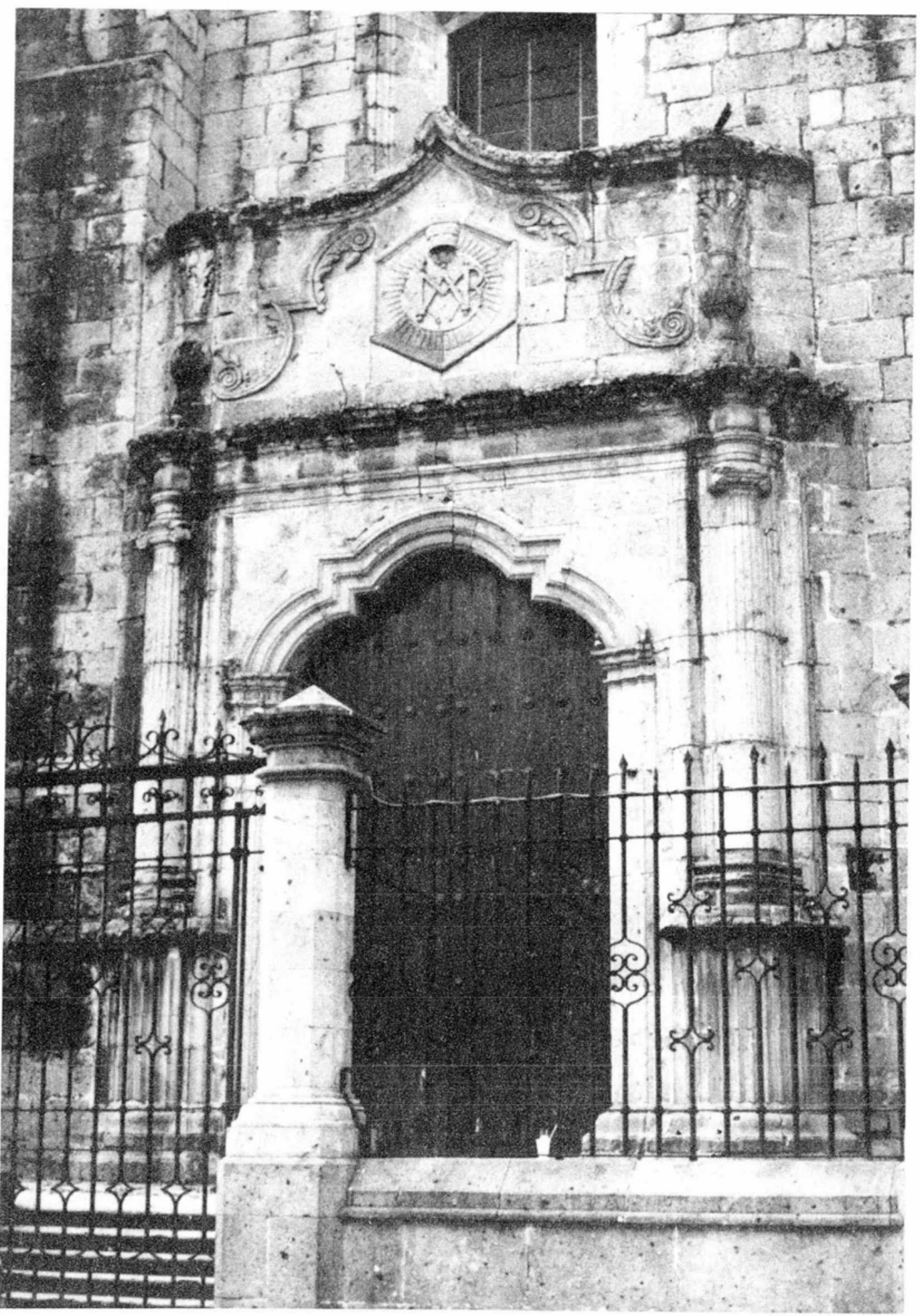

Figura 14. Portada lateral en la iglesia de La Compañía. 
DOI: http://dx.doi.org/10.22201/iie.18703062e.1987.58.1370

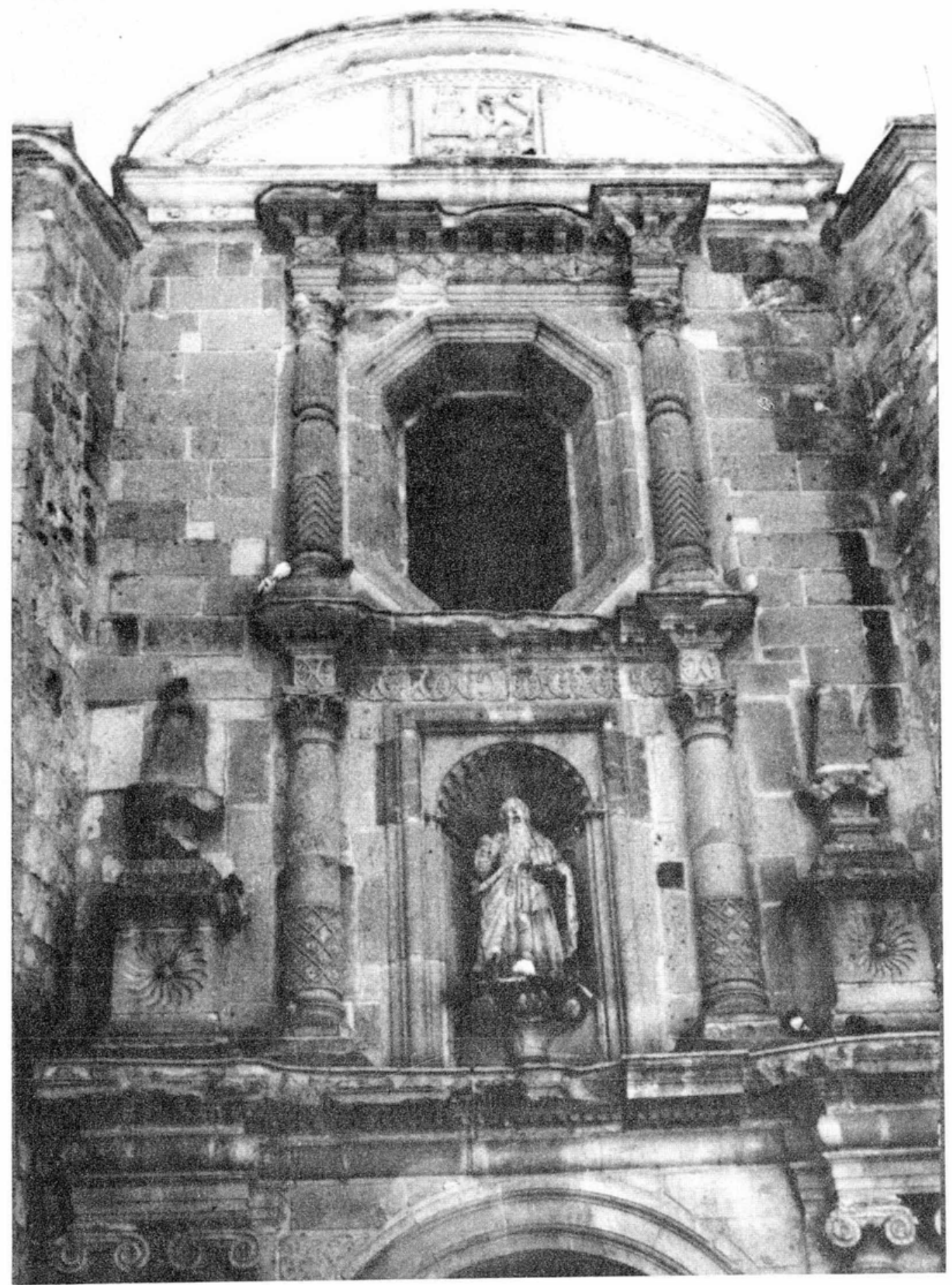

Figura 15. Sección alta de la portada del crucero norte de la catedral. 
DOI: http://dx.doi.org/10.22201/iie.18703062e.1987.58.1370

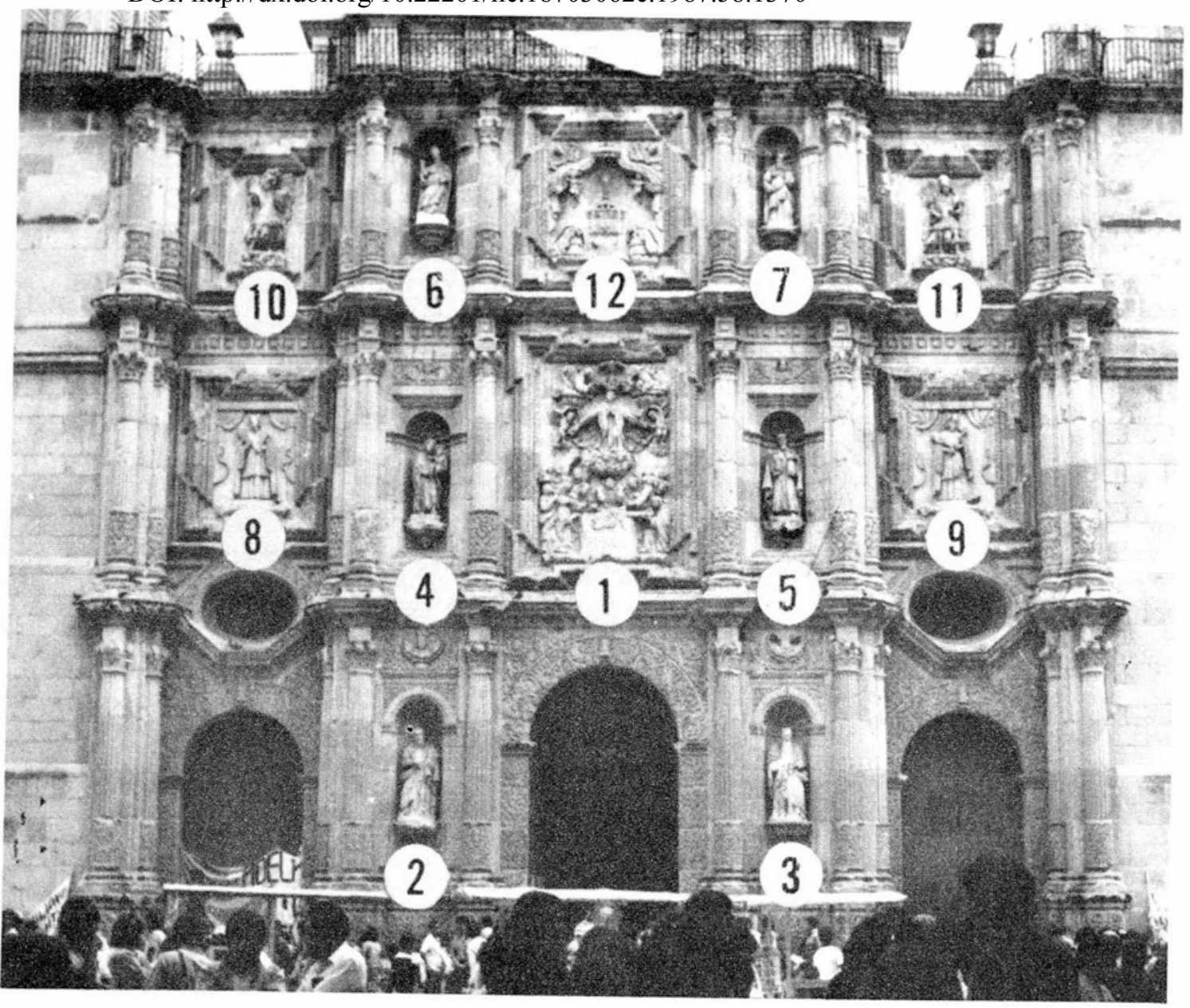

Figura 16. Fachada mayor de la catedral con intención de identificaciones iconográficas y sugerencias de mensaje iconológico.

*NOTA: Todas las figuras son fotografías del autor. 
DOI: http://dx.doi.org/10.22201/iie.18703062e.1987.58.1370

L $\quad A \quad M \quad I N \quad N \quad A \quad S$ 
**Nota. La lámina número 1 se tomó de la Historia del Arte Hispano Americano, Diego Angulo Iñiguez, tomo I, p. 448, Salvat Editores, S. A., Barcelona, 1955.

Las láminas 2 y 3 se obtuvieron de Las catedrales de Oaxaca, Morelia y Zacatecas, José R. Benítez, pp. 9 y 12, Talleres Gráficos de la Nación, México, 1934.

La lámina 4 es una superposición teórica hecha por el autor sobre la lámina núm. 9 del antecitado estudio de José R. Benítez. La lámina 5, procede de la revista Artes de México, número doble, 70-71 dedicado a Oaxaca. Año XII, México, 1965. 


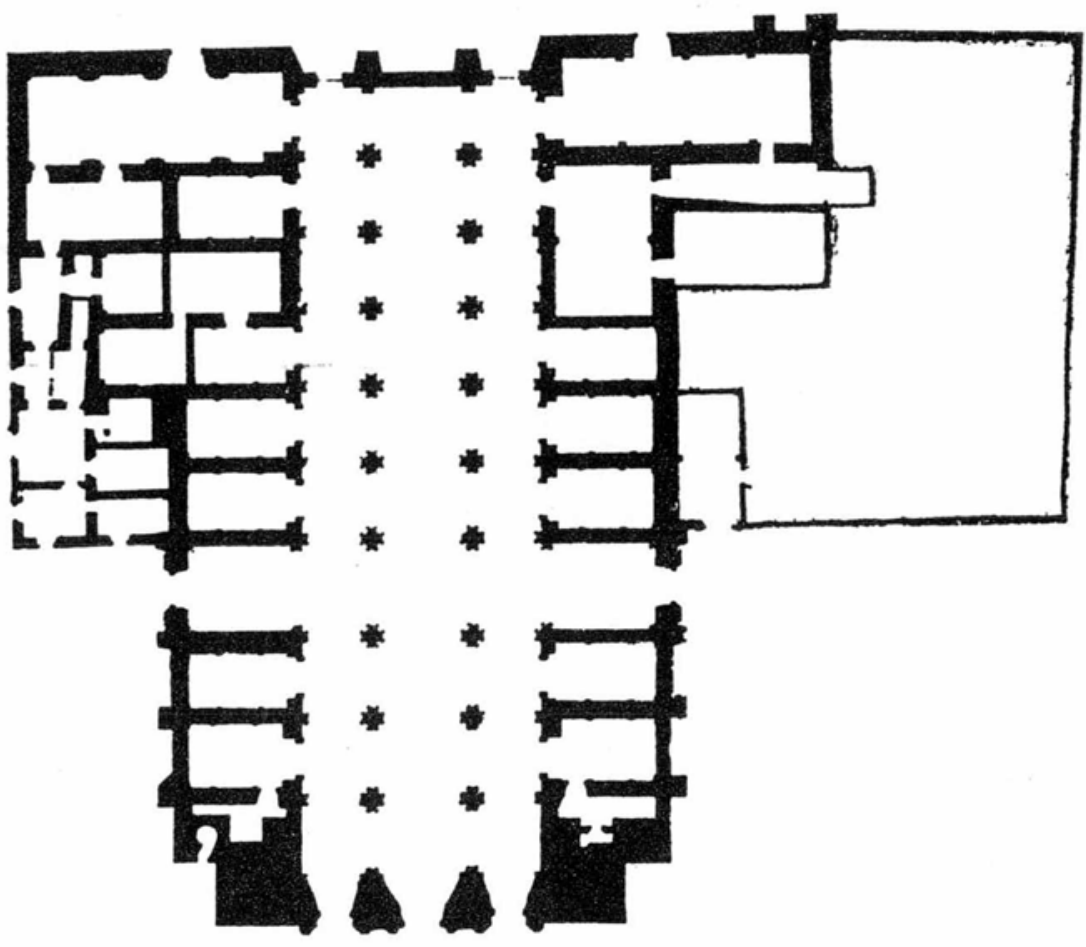

Lámina 1. Plano de la catedral de Oaxaca levantado por Enrique Cervantes. Nótese la macicez, producto del temor, en el reforzamiento de la sección de fachada que podría "desbocarse" hacia el frente. En tanto, las naves se aligeran apoyándose en sus costados en la profundidad de las capillas que sirven de prolongados contrafuertes, a manera de brazos extendidos y equilibrantes. 
CATEDRAL DE OAXACA.

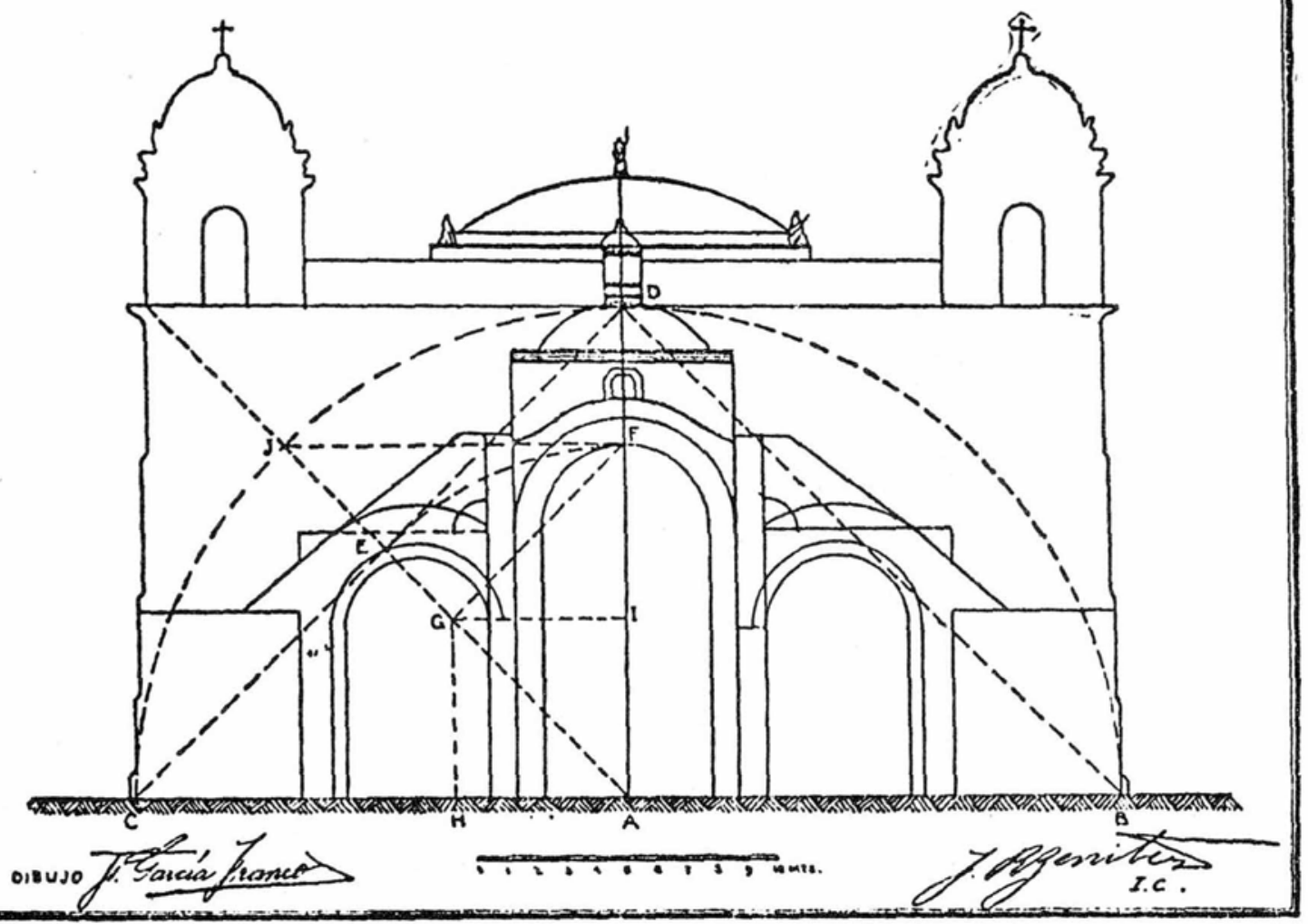

Lámina 2. Trazado de las proporciones armónicas de la catedral de Oaxaca, según José R. Benítez. 


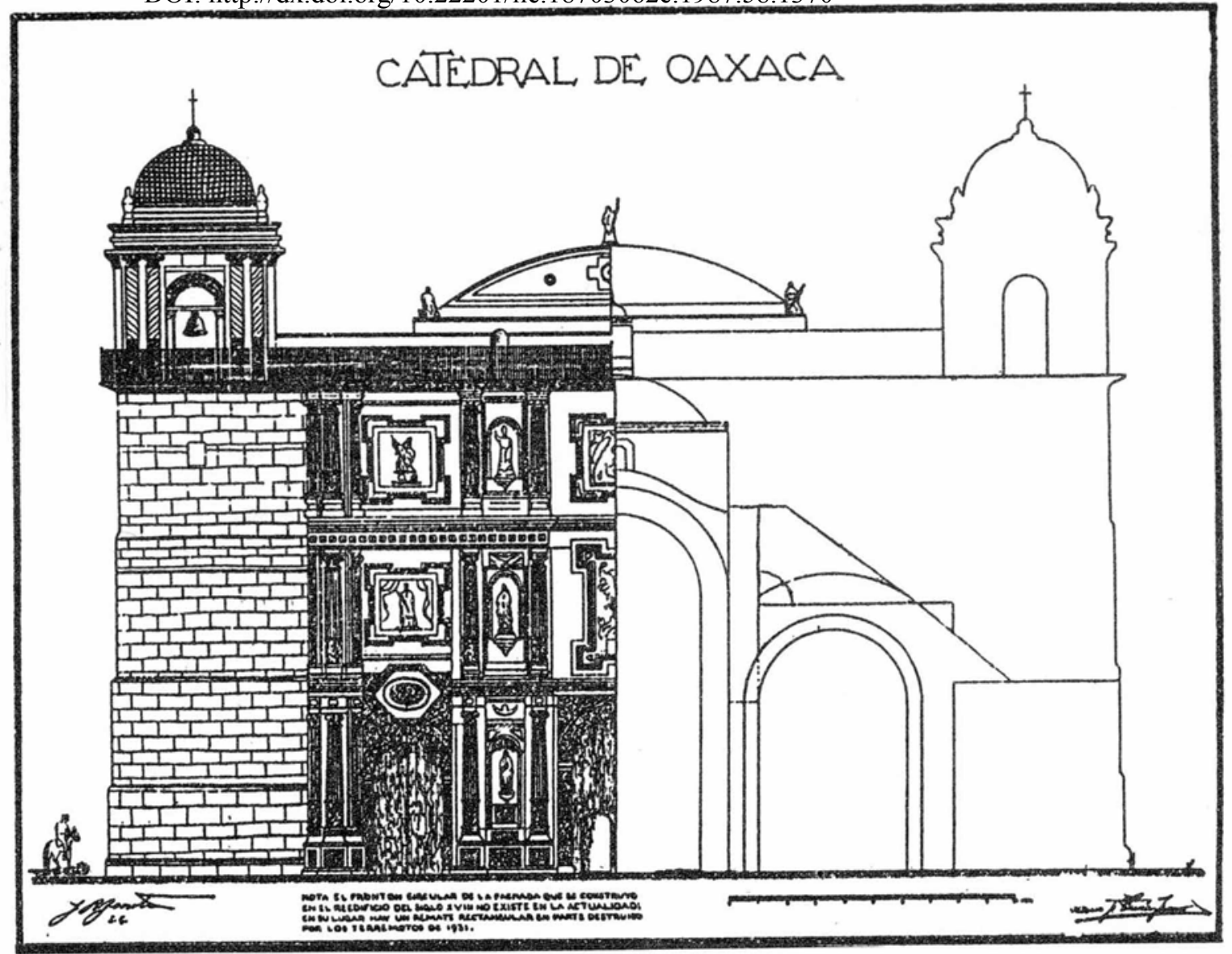

Lámina 3. Alzado de las naves y fachada de la catedral de Oaxaca, según José R. Benítez. 


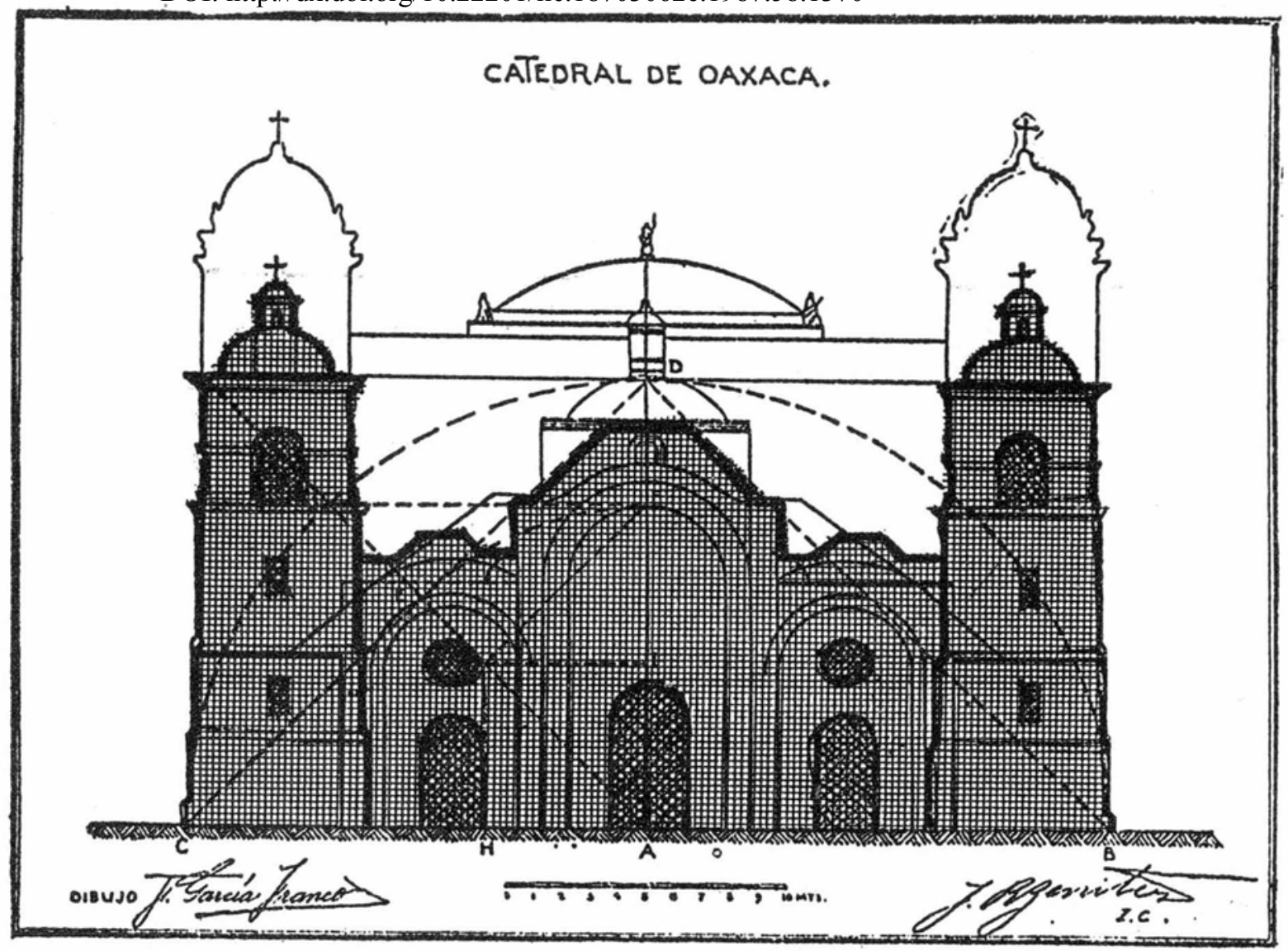

Lámina 4. Posible volumetría y perfil general primitivo de la catedral de Oaxaca, según deducciones expuestas en este trabajo. Puede observarse cómo existe una mejor concordancia entre los trazos de composición armónica propuestos por Benítez y el aspecto original o rostro oculto de la catedral que por nuestra parte suponemos y cómo respondía de mejor manera aquel exterior al actual interior. 


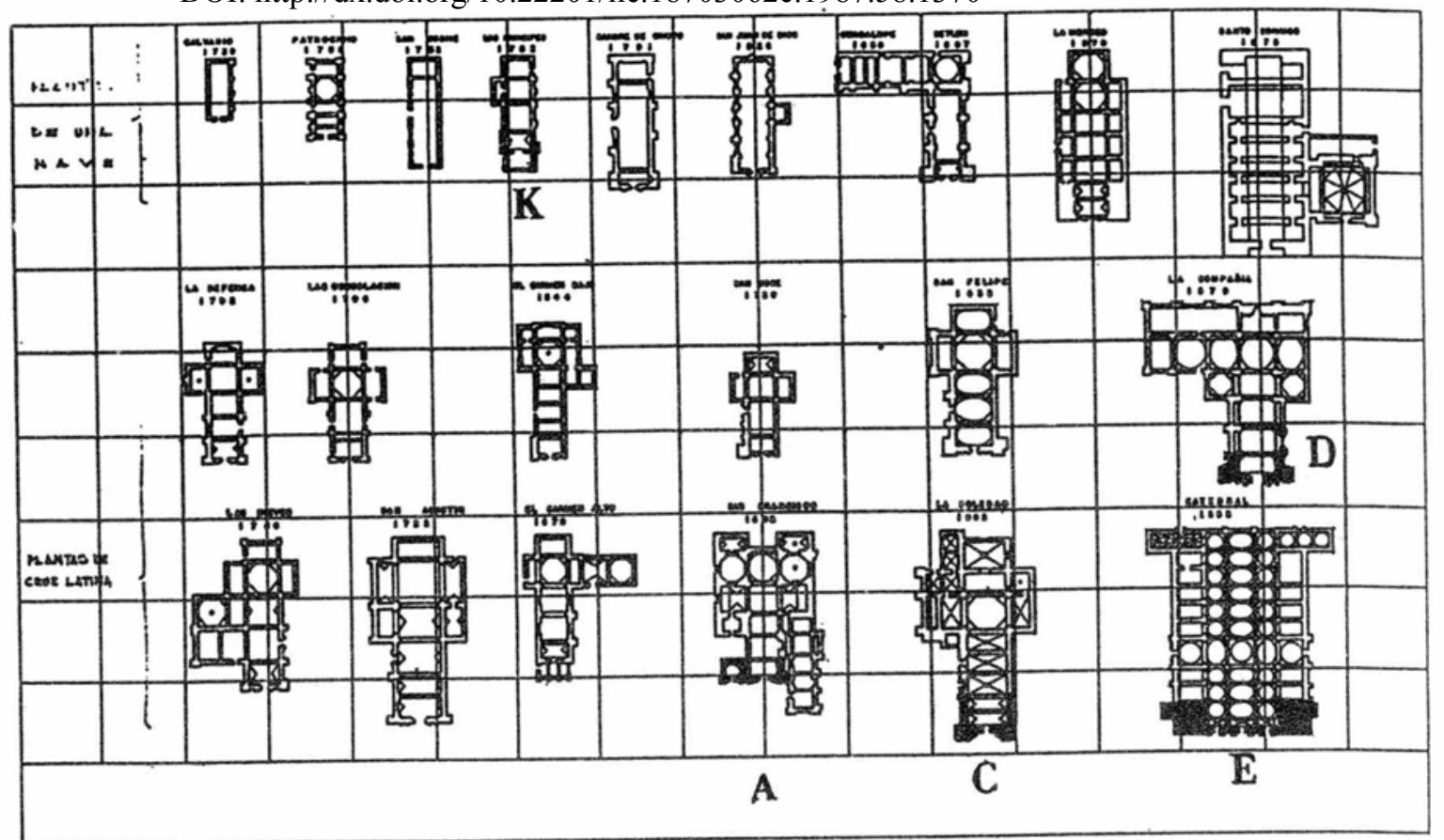

Lámina 5. Plantas de las iglesias de la ciudad de Oaxaca. Comparándose la disposición de algunas de sus fachadas con letras mayúsculas del abecedario a saber: E, Catedral. C, La Soledad. A, San Francisco. D, La Compañía y K, Los Príncipes. 